\title{
Aquarius and Remote Sensing of Sea Surface Salinity from Space
}

\author{
D.M. Le Vine \\ Goddard Space Flight Center, Greenbelt,MD \\ G.S.E. Lagerloef \\ Earth and Space Research, Seattle, WA \\ S. Torrusio \\ Comision Nacional Actividades Espaciales
}

\begin{abstract}
Aquarius is an L-band radiometer and scatterometer instrument combination designed to map the salinity field at the surface of the ocean from space. The instrument is designed to provide global salinity maps on a monthly basis with a spatial resolution of $150 \mathrm{~km}$ and an accuracy of $0.2 \mathrm{psu}$. The science objective is to monitor the seasonal and interannual variation of the large scale features of the surface salinity field in the open ocean. This data will promote understanding of ocean circulation and its role in the global water cycle and climate. Aquarius is the primary instrument on the Aquarius/SAC-D mission, a partnership between the USA (NASA) and Argentina (CONAE). Launch is scheduled for May, 2010.
\end{abstract}

\section{INTRODUCTION}

Aquarius is a combined active/passive L-band microwave instrument designed to map the surface salinity field of the oceans from space. It will be flown on the Aquarius/SAC-D mission, a partnership between the USA space agency (NASA) and Argentine space agency (CONAE). The mission is composed of two parts: (a) Aquarius, a radiometer/scatterometer instrument combination for measuring sea surface salinity, which is being developed as part of NASA's Earth System Science Pathfinder (ESSP) program; and (b) SAC-D, which is the fourth spacecraft service platform in the CONAE Satelite de Aplicaciones Cientificas (SAC) program and will include several additional instruments. The primary focus of the mission is to monitor the seasonal and interannual variations of the salinity field in the open ocean. The mission also meets the needs of the 
Argentine space program for monitoring the environment and for hazard detection. The objective of this paper is to give an overview of the mission with emphasis on Aquarius and the issues associated with monitoring salinity from space. The manuscript divides into two parts: Sections II-IV which provide background on the science objectives of Aquarius and the physics of remote sensing of ocean salinity; and Sections V-VI which describe the Aquarius/SAC-D mission and give an overview of the Aquarius instrument.

\section{SCIENCE OBJECTIVES}

The goal of Aquarius is to monitor the seasonal and interannual variation of the large scale features of the sea surface salinity (SSS) field in the open ocean. The instrumentation has been designed to provide monthly maps with a spatial resolution of $150 \mathrm{~km}$ and an accuracy of $0.2 \mathrm{psu}$. These are requirements derived from the need to better understand the buoyancy driven thermohaline circulation of the ocean and its relationship to climate and the global water cycle.

The thermohaline circulation moves large masses of water and heat around the globe. On the large scale, cold and dense water sinks in high latitudes and ventilates the ocean interior. An example of the surface limb of this circulation is the relatively warm salty waters of the Gulf Stream which transports heat to the northern latitudes and moderates the climate of Europe. Pre-historic climate events have been linked to the strength of the thermohaline circulation, which is particularly dependent on surface salinity variations in the subpolar North Atlantic [Broecker, 1991]. Of the two variables that determine buoyancy (salinity and temperature), temperature is already being monitored from space [e.g. Gentemann et al, 2004]. The surface salinity field is the missing variable needed to understand this circulation.

An example of the importance of salinity is the "great salinity anomaly" of the 1970's in which a large water mass of relatively fresh water circulated around the North Atlantic subpolar gyre and apparently modified the inflow of warm water from the Gulf Stream leading to a period of cool temperature in northern Europe [Dickson et al, 1988]. Increased freshening in the form of freshwater flux from melted ice is expected in the 
future [Bindoff et al, 2007] and knowledge of the dynamics of the SSS field in the north Atlantic will help better understand the potential impact of such melting on ocean circulation and climate change in this region.

Salinity also plays an important role in energy exchange between the ocean and atmosphere in other ways. For example, in areas of strong precipitation, fresh water "lenses" can form on the surface [Sprintall and Tomzcak, 1992]. These are buoyant layers of water that form stable layers and insulate the water in the mixed layer below from the atmosphere [Lukas and Lindstrom, 1991]. This alters the air-sea coupling (energy exchange) and can affect the evolution of tropical intra-seasonal oscillations, monsoons and the El Nino-Southern Oscillation (ENSO).

Salinity is also an indicator for tracking the global water cycle. Water fluxes between the ocean and atmosphere dominate the global hydrologic cycle, accounting for $86 \%$ of global evaporation and 78\% of global precipitation [Schmitt, 1994]. Changes in surface salinity reflect changes in surface freshwater forcing. Systematic mapping of the global salinity field will help to reduce the wide uncertainties in the marine freshwater budget [Johnson et al, 2002] and will help to better understand the global water cycle and how it is changing.

The need for measurements of salinity on a global scale has recently been articulated in the U.S. Climate Variability Program (CLIVAR) science planning (Oceanography Magazine, 2008; Lagerloef, et al, 2008). The time and spatial scale of observations needed to improve understanding of processes in the open ocean are relatively long (months and hundreds of kilometers, respectively) but the associated salinity changes are relatively small (tenths of a psu) [Lukas and Santiago-Mundujano, 2008]. This is in contrast to processes in the coastal ocean where changes can be several psu but time and spatial scales are on the order of days and kilometers. New technology, perhaps aperture synthesis [Le Vine et al, 1999; Font et al, 2009], is needed to achieve the high spatial resolution at low microwave frequencies (L-band) needed to address the coastal ocean. 
Aquarius is designed to focus on the open ocean. The goal for the Aquarius instrument is to provide global maps of the sea surface salinity field in the open ocean on a monthly basis with an average accuracy of $0.2 \mathrm{psu}$ and at a spatial resolution of $150 \mathrm{~km}$. In comparison, the existing database is too sparse in both time and space to resolve key processes. For example, dividing the ice-free ocean into one-degree squares in latitude and longitude, one finds that about $25 \%$ has never been sampled and more than $73 \%$ has fewer than 10 samples [Koblinsky et al, 2003; Lagerloef et al, 1995]. The sparse data is primarily a reflection of the limitations of in situ sampling and is worse in the southern oceans than in the north. In contrast, Aquarius will completely map the global ice-free ocean every 7-days from which monthly average composites will be derived. This will provide a snapshot of the mean field, as well as resolving the seasonal to interannual variations over the three-year baseline of the mission.

\section{Measurement Physics}

\section{A. Introduction}

Salinity changes the microwave emissivity of ocean water causing a change of about $0.5 \mathrm{~K} / \mathrm{psu}$ at L-band. This is well within the capability of modern microwave radiometers to measure [Blume et al, 1978; Le Vine et al, 1998]. The radiometric sensitivity to changes in salinity is a strong function of frequency and decreases rapidly above about 1 GHz. The radio astronomy window at $1.413 \mathrm{GHz}$ (L-band) provides a quiet piece of spectrum with adequate bandwidth, and most research on remote sensing of salinity has

been done there. But at low microwave frequencies antenna size becomes a technological challenge and is the factor limiting spatial resolution from space. Radiometric accuracy is also an important issue because the accuracy required for ocean processes important for climate studies, $0.2 \mathrm{psu}$, is small in radiometric units (about 0.1 $\mathrm{K})$. While this can be achieved with good design, competing factors such as Faraday rotation and surface roughness must also be taken into account when making measurements from space at L-band. In the sections below a brief background is presented of the physics behind the measurement of salinity and of the issues associated with monitoring salinity from space. 


\section{B. Microwave Radiometry}

The configuration for microwave remote sensing of the oceans is illustrated in Figure 1. At microwave frequencies, the thermal radiation emitted by an ideal "blackbody" is given to good approximation by the Rayleigh-Jean law:

$$
\mathrm{B}(\mathrm{f})=2 \mathrm{kT}_{\text {phys }} / \lambda^{2} \quad \mathrm{~W} / \mathrm{m}^{2}-\mathrm{Sr}-\mathrm{Hz}
$$

where $\mathrm{k}$ is Boltzmann's constant, $\mathrm{T}_{\text {phys }}$ is the physical temperature of the object, $\lambda=\mathrm{c} / \mathrm{f}$ is the wavelength and $f$ is frequency. Equation 1 is the total power per unit area emitted per unit bandwidth (i.e. per hertz) in unit solid angle (i.e. per steradian). It is called the "brightness" although "spectral brightness" is also used and in optics B(f) is called "radiance" [Ulaby et al, Section 4.2-1]. In the case of real objects, such as the ocean surface, it is conventional to use Equation 1 with $T_{\text {phys }}$ replaced by an effective temperature, $\mathrm{T}_{\mathrm{B}}(\Omega, \mathrm{f})$, called the "brightness temperature" and to write:

$$
\mathrm{B}(\mathrm{f})=2 \mathrm{kT}_{\mathrm{B}} / \lambda^{2} \quad \mathrm{~W} / \mathrm{m}^{2}-\mathrm{sr}-\mathrm{Hz}
$$

where

$$
\mathrm{T}_{\mathrm{B}}(\mathrm{f})=\mathrm{e}(\mathrm{f}) \mathrm{T}_{\text {phys }}
$$

The term e $(\mathrm{f})$ is called the "emissivity". In the case of the ocean surface, the emissivity depends on salinity but it also depends on the physical temperature and surface roughness (waves) as well as other parameters such as incidence angle, frequency and polarization.

The radiation emitted by the surface is measured with a "microwave radiometer" as illustrated in Figure 1. The radiation is collected by the antenna and amplified in the receiver. Assuming ideal functions for each (i.e. ignoring losses and engineering details of implementation) and assuming a receiver with unit gain over its bandwidth, one obtains the following expression for the output power at polarization $\mathrm{p}$ [Kraus, 1966; Ulaby, Moore and Fung, 1981, Section 4-2.1]: 


$$
\mathrm{W}_{\mathrm{p}} \quad=\quad(1 / 2) \mathrm{A}_{\mathrm{e}} \iint \mathrm{B}(\Omega, \mathrm{f}) \mathrm{P}_{\mathrm{np}}(\Omega) \mathrm{d} \Omega \mathrm{df}
$$

where $A_{e}$ is the effective area of the antenna, $P_{n p}$ is the normalized antenna pattern for polarization, and the subscript " $p$ " indicates polarization (e.g. horizontal or vertical). It is conventional in microwave radiometry to express Equation 3 in terms of effective temperatures. This is done by replacing the left-hand side by the change in temperature this power would cause in a matched resistor at the output:

$$
\mathrm{W}_{\mathrm{p}}=\mathrm{kT}_{\mathrm{Ap}} B_{w}
$$

$\mathrm{T}_{\mathrm{Ap}}$ is called the "antenna temperature" and $B_{w}$ is the bandwidth of the measurement system. Using Equations 2 and 4 in Equation 3, and assuming that $T_{B}$ and $P_{n}$ are independent of frequency over the passband of the measurement system and that the bandwidth, $B_{w}$, is narrow compared to the center frequency, one obtains:

$$
\begin{aligned}
\mathrm{T}_{\mathrm{Ap}} & =\left(1 / \Omega_{\mathrm{B}}\right) \iint \mathrm{T}_{\mathrm{B}}(\Omega) \mathrm{P}_{\mathrm{np}}(\Omega) \mathrm{d} \Omega \\
& =\quad(1 / 4 \pi) \iint \mathrm{e}(\Omega) \mathrm{T}_{\text {phys }} \mathrm{G}_{\mathrm{np}}(\Omega) \mathrm{d} \Omega
\end{aligned}
$$

where the relationship $A_{e}=\lambda^{2} / \Omega_{B}$ has been used in Equation 5 to obtain an expression in terms of the antenna solid angle, $\Omega_{\mathrm{B}}$. Equation 5 is a classic result in microwave radiometry relating the observable, the antenna temperature, $\mathrm{T}_{\mathrm{Ap}}$, to the source brightness temperature $\mathrm{T}_{\mathrm{B}}(\Omega)$ [e.g. Ulaby et al, 1981, section 4-5.3]. Equation 6 is a variation in which the relationship $G_{n p}=4 \pi\left(P_{n p} / \Omega_{B}\right)$ has been used to obtain an expression in terms of antenna gain, $\mathrm{G}$, and Equation $2 \mathrm{~b}$ has been used to illustrate the dependence on emissivity.

\section{Example: Remote Sensing of Salinity}


The dependence of the thermal emission from the ocean on salinity is contained in the emissivity, e(f). The emissivity is a complex quantity that depends on physical and chemical properties of the water (e.g. salinity and temperature) and also geometry of the surface (e.g. waves). The characterization is greatly simplified if one ignores waves (flat ocean surface). For example, consider a planar boundary between a uniform upper halfspace (air) and a uniform lower half-space (water). Assuming a system in equilibrium, conservation of energy can be used to relate the emissivity to reflectivity [Peake, 1959]:

$$
\mathrm{e}(\theta)=1 \quad-\quad \mathrm{R}(\theta)
$$

Because the media above and below is homogenous, the reflectivity, $R(\theta)$, can be expressed in term of the Fresnel reflection coefficient for a flat surface $R(\theta)=|r(\theta)|^{2}$. For a plane surface, one obtains [Plonsey and Collin. 1961]:

$$
\begin{aligned}
& \sqrt{ }\left\{\varepsilon-\sin ^{2}(\theta)\right\}-\varepsilon \cos (\theta) \\
& \sqrt{ }\left\{\varepsilon-\sin ^{2}(\theta)\right\}+\varepsilon \cos (\theta) \quad \text { Vertical Polarization } \\
& \mathrm{r}(\theta)= \\
& \sqrt{ }\left\{\varepsilon-\sin ^{2}(\theta)\right\} \quad-\cos (\theta) \\
& \sqrt{ }\left\{\varepsilon-\sin ^{2}(\theta)\right\}+\cos (\theta)
\end{aligned}
$$

In the expression above, $\varepsilon$ is the relative dielectric constant of the lower half-space and $\theta$ is the angle the boresight direction of the antenna makes with the normal to the surface (there is no dependence on azimuth, $\varphi$ in this case). In the special case of normal incidence $(\theta=0)$, the distinction between polarizations disappears and one has:

$$
\mathrm{e}(0)=4 \operatorname{Re}(\sqrt{\varepsilon}) /|(1+\sqrt{\varepsilon})|^{2}
$$

The dielectric constant of sea water at microwave frequencies gained considerable attention in the last quarter of the $20^{\text {th }}$ century both because of the interest in remote sensing of salinity [e.g. Klein and Swift, 1977; McIntosh and Swift, 1983] and because it is also important in microwave remote sensing of sea surface temperature [Stogryn, 1971; 
Meissner and Wentz, 2004; Ellison et al, 1998]. The expression used most often at Lband for remote sensing of salinity is that proposed by Klein and Swift [1977]. Although successful, this model is based on a relatively limited set of measurements at $1.4 \mathrm{GHz}$ and the need for an accurate model function at L-band for use by SMOS and Aquarius led to a new wave of measurements [Blanch and Aguasca, 2004; Lang et al, 2008]. The early work used a Debye model for the contribution of the water molecule to provide an expression valid over a range of frequency [e.g. Stogryn, 1995; Klein and Swift, 1977]. However, the recent investigations [Blanch and Agusca, 2004; Lang et al, 2008] have focused on measurements at a single frequency $(1.413 \mathrm{GHz})$ over a range of salinity and temperature. This work is still in progress [Lang et al, 2009].

Figure 2 is an example of the effect of salinity on emission from sea water at L-band. Brightness temperature, $T_{B}$, is plotted on the ordinate and the physical temperature of the water (SST) has been plotted along the abscissa for different values of salinity. The computations were made using the Klein and Swift [1977] expression for the dielectric constant of sea water. The shaded area in Figure 2 indicates the range of salinity typical of the open ocean (e.g. away from the coast) and gives an idea of the dynamic range to be expected of the radiometric signal.

The sensitivity of the measurement to changes in salinity (i.e. the ratio of the change in $T_{B}$ due to a change in salinity) corresponds roughly to the spacing between the level curves of constant salinity. It is clear from Figure 2 that the sensitivity decreases in cold water. The sensitivity is also a function of frequency and incidence angle. This is illustrated in Figure 3 in the case $T_{\text {phys }}=20^{\circ} \mathrm{C}$ and SSS $=35 \mathrm{psu}$. The dashed curve is for nadir $(\theta=0)$ and the solid curves indicate the sensitivity at 40 degrees. Notice that when $\theta \neq 0$, vertical polarization (upper curve) is more sensitive than horizontal polarization (lower curve). In general, the sensitivity at $1.413 \mathrm{GHz}$ is in the range of $0.4-0.6 \mathrm{~K} / \mathrm{psu}$ depending on polarization and incidence angle. Only the magnitude of the sensitivity has been plotted in Figure 3. The sign is negative (decreasing $T_{B}$ for an increase in salinity). Also note that the sensitivity peaks around $600 \mathrm{MHz}$. Proposals have been made for remote sensing from space at frequencies closer to the peak than the L-band window 
[McIntosh and Swift, 1983]. However, the limited bandwidth available at other windows and the prevalence of manmade noise make this impractical.

In its simplest form, the remote sensing problem consists of a measurement of the brightness temperature (for an ideal antenna $T_{A}=T_{B}$ ) together with an independent measure of SST. The intersection of the two values on a graph such as shown in Figure 2 gives SSS. The accuracy is determined by the error in estimating $T_{B}$ from the measured $\mathrm{T}_{\mathrm{A}}$ and the error in SST. Of course, the accuracy of the level curves is also a factor; hence, the continuing interest in measurements of the dielectric constant at $1.413 \mathrm{GHz}$. There are also other issues that complicate the remote sensing problem in the real world of monitoring salinity from space. These are discussed in Section IV.

\section{Remote Sensing Heritage}

The measurement of sea surface salinity remotely with a microwave radiometer has been demonstrated in experiments that date back to the 1970's. For example, Droppelman et al, [1970] reported observing salinity variations in outflow of the Mississippi River with an airborne radiometer, and Lerner and Hollinger [1977] reported differences associated with salinity in the response of the L-band radiometer that flew on SkyLab. In the late 1970's an extensive series of measurements was conducted at NASA's Langley Research Center that demonstrated the feasibility of monitoring salinity with airborne radiometers. The approach was to use two frequencies (L-band and S-band) to eliminate the need for an independent measure of surface temperature [Blume et al, 1978; 1981; Blume and Kendal, 1982]. However, the narrow bandwidth available for passive measurements at Sband $(2.65 \mathrm{GHz})$ and the prevalence of man-made noise (RFI) in this portion of the spectrum made use of S-band impractical and the latest reports were of the use of measurements in the window at $1.413 \mathrm{GHz}$ together with an independent measure of temperature [e.g. Kendal and Blanton, 1981]. Research was also conducted at the Langley Research Center at this time to improve the model function for the dependence of the dielectric constant on salinity [Klein and Swift, 1977] and a proposal was made for remote sensing from space [Swift and MacIntosh, 1983]. 
In the 1990's new research was conducted at the NASA Goddard Space Flight Center, this time in the context of new technology, aperture synthesis, which had the potential to make remote sensing from space at long wavelengths practical [Le Vine, 1999]. This is the technology soon to be demonstrated in space by the MIRAS radiometer on ESA's SMOS mission [Font et al, 2009]. Experiments in the vicinity of the Delaware River plume demonstrated accuracies on the order of 1 psu [Le Vine et al, 1998]. Experiments were also conducted further off shore to obtain conditions more representative of the open ocean. Figures 4 and 5 show results from an experiment that took place in 1999 east of Delaware Bay in the vicinity of a warm core eddy from the Gulf Stream. The experiment consisted of in situ mapping using shipborne thermosalinographs and remote sensing from NASA's P-3 aircraft using the ESTAR L-band radiometer [Le Vine, Swift and Haken, 2001]. Figure 4 (top) shows the track of the ships and the salinity map derived from the thermosalinographs; and Figure 4 (bottom) shows a comparison of the salinity derived from ESTAR measurements and the shipborne observations. The comparison is along the track with the nearest time coincidence between ship and aircraft (the aircraft flew over the ship along this track). Figure 5 shows the composite SSS field derived from the ship observations (right) and airborne observations (left). Some of the differences are attributable to the time differences required by the two sources to make the map: the ship map is a composite of measurements over three days but the aircraft required only a few hours to map the same region.

Airborne remote sensing of salinity is an on-going endeavor. Research has been conducted in Europe in preparation for the SMOS mission using both conventional and interferometric (i.e. synthetic aperture) radiometers [Kainulainen, et al, 2007; Berger et al, 2002] and research with a focus on the coastal ocean has been supported by US Navy [Burrage et al, 2008; Miller, 2000]. Remote sensing from space with the spatial resolution needed to address issues of the coastal zone continues to be a research challenge.

\section{REMOTE SENSING SALINITY FROM SPACE}


Figure 6 shows the Aquarius radiometer looking down from its orbit in space toward the ocean. The goal is to measure the thermal emission from the surface (bold solid line) and to use this signal together with knowledge of the SST to obtain an estimate of the sea surface salinity (SSS). Conceptually, this is straight forward: One measures $\mathrm{T}_{\mathrm{B}}$ and, with knowledge of SST, uses a look-up table or graph such as Figure 2 to find the value of salinity that corresponds to the intersection. The accuracy depends on how well SST is known; how well the instrument response (e.g. Equation 5) can be inverted to obtain the brightness temperature, $\mathrm{T}_{\mathrm{B}}$; and how well the level curves of constant salinity are known. Aquarius will use the best available estimates of SST (e.g. the GODAE high resolution sea surface temperature pilot project, Donlon et al, 2007) and best available model for the level curves (e.g. see Section III.C). However, making the measurement from space in the real world at L-band involves additional issues. These are illustrated in Figure 6 and discussed briefly below.

A primary issue when measuring from space is the propagation path. At L-band, scattering in the atmosphere and the dependence on clouds and water vapor are small [Yueh et al, 2001]. However, emission from the atmosphere must be taken into account in order to achieve the accuracy needed for remote sensing of salinity. This includes both upwelling emission (about $1.9 \mathrm{~K}$ at nadir; Yueh et al, 2001) and downwelling radiation that is reflected from the surface (dashed lines). The approach adopted for Aquarius is to use conventional radiative transport theory to model attenuation and emission from the atmosphere [e.g. Blume and Kendall, 1982] and to obtain the parameters such as temperature and pressure profiles needed in the model from measurements and meteorlogical models such as provided by the National Center for Environmental Prediction (NCEP). The emission at L-band is weakly dependent on atmospheric conditions [Yeuh et al, 2001] and modern models exist to predict its value [Liebe, Rosenkranz and Hufford, 1992; Thompson, Moran and Swenson, 1986]; however direct measurements of the emission from the atmosphere at the accuracy needed for remote sensing of salinity haven't been made at L-band. As a result some uncertainty exists that will have to be determined once the sensor is in orbit. 
Liquid water in the form of rain can also be important at L-band at the accuracy required for monitoring of salinity. In the case of Aquarius, areas where rain is likely will be flagged using weather models and other satellite data. In addition, the Aquarius/SAC-D observatory will include a Microwave Radiometer (MWR) operating at 23.8 and 36.5 $\mathrm{GHz}$ (see Section V). The MWR will have a rain product with a foot print that is designed to cover the field-of-view of Aquarius (Figure 7).

In the case of a sensor in space, the propagation path also includes the ionosphere. Attenuation and emission in the ionosphere are not important at L-band [Le Vine and Abraham, 2002]; however, the Earth's magnetic field makes the ionosphere birefringent causing the polarization of electromagnetic waves propagating through the ionosphere to rotate (Faraday rotation). This is an issue because the emissivity of the surface depends on polarization (e.g. Equation 8). The orbit planned for Aquarius (sun-synchronous with ascending equatorial crossings at $6 \mathrm{pm}$ ) avoids the mid-day maximum electron density of the ionosphere, but the potential remains for enough rotation of the polarization vector to warrant correction [Le Vine and Abraham, 2002]. Also, Aquarius is scheduled to operate during a peak in the solar cycle which corresponds to increased ionization. Models of the ionosphere, especially over the ocean where data is limited, are improving but are not sufficiently accurate to meet the Aquarius goal of 0.2 psu. To address this problem, the Aquarius radiometer will measure the third Stokes parameter (correlation between vertical and horizontal polarization) in addition to radiation at vertical and horizontal polarization. The ratio of the third Stokes parameter to the difference between vertical and horizontal polarization can be used to retrieve the rotation angle. Although the theory is well known [Yueh, 2000], there are issues associated with implementing it with real antennas [Le Vine et al, 2007] and this approach must be tested in space.

Another issue associated with remote sensing at L-band in the real world is the presence of unwanted radiation. Emission from the atmosphere is an example. At L-band there are several other sources that can be important for remote sensing of salinity. One of these is radiation from outer space. The window at $1.413 \mathrm{GHz}$ was restricted to passive use because it is centered on an emission line of hydrogen and was needed for radio 
astronomy studies of the distribution of hydrogen in our galaxy. In addition to hydrogen, radiation from sources with a broad spectrum (e.g. thermal sources) and also the cosmic background radiation are important at L-band. The dominant mode of interference is radiation that is reflected from the surface into the main antenna beam (dot-dash line in Figure 6). The total contribution can be more than $12 \mathrm{~K}$ in the direction of the plane of the galaxy even when smoothed by the aperture of large antennas like Aquarius (Le Vine and Abraham, 2006). Fortunately, modern surveys have been made by the radio astronomy community of these sources and a model for the L-band "sky" exists that can be used to characterize the contribution of these sources (Le Vine and Abraham, 2004; Wolleben et al, 2006). An open issue that will most likely not be resolved until after launch is the impact of surface roughness on this signal [Dinnat and Le Vine, 2008; Reul et al, 2007].

The Sun and Moon are also sources of radiation at L-band. In the microwave range, the sun is a very hot thermal source with effective temperatures on the order of $10^{6}$ degrees during active periods of the solar cycle [Le Vine et al, 2005; Ruel et al, 2007]. Solar flares can be even hotter. Even though the sun is relatively small in angular extent, it is such a strong and variable radiator at L-band that radiation from the sun constitutes one of the most important potential sources of error [Le Vine, et al, 2005]. The Aquarius/SAC-D spacecraft observatory will be in a nearly polar, sun-synchronous orbit which exposes it to both direct radiation from the sun and also radiation reflected from the ocean surface into the radiometer. Several steps have been taken in the design and orientation of Aquarius to minimize the impact radiation from the Sun. The orbit of the Aquarius/SAC-D spacecraft lies close to the day-night terminator (equatorial crossings at 6 am and $6 \mathrm{pm}$ ) and to minimize the impact of reflected solar radiation, the antenna boresights are directed across track toward the night-time side of the ground track (i.e. away from the sun as illustrated in Figure 7). Direct and reflected radiation from the Sun can not be avoided, but in this configuration they reach the radiometer in the far sidelobes of the antenna. In addition, special attention has been given in the design of the Aquarius antennas to minimize the sidelobes in the direction of both the direct ray and the reflected ray. Surface roughness complicates the problem, and at certain times of the year it is 
possible for scattered radiation from the sun to enter near the main lobe [Dinnat and Le Vine, 2008]. These situations are predictable and will be flagged for examination.

Radiation from the moon at L-band is primarily due to its own thermal emission and is usually negligible. However, during short periods that occur twice in each lunar cycle, this radiation will reflect directly into the main beam of the antenna causing changes in antenna temperature as much as $1 \mathrm{~K}$ [Dinnat et al, 2009]. These events are relatively short (1\% of observations) and can be predicted accurately. The plan for Aquarius is to flag these time intervals for analysis later.

Another factor that complicates remote sensing of salinity from space is the presence of land in the field of view. At L-band, land is radiometrically much warmer than ocean (on the order of $300 \mathrm{~K}$ for land compared to $100 \mathrm{~K}$ for ocean). Given an accuracy goal of about $0.1 \mathrm{~K}$ (roughly $0.2 \mathrm{psu}$ ), even small amounts of land within the foot print can bias the retrieval of salinity. As a result, the required accuracy will be achieved only in the open ocean several beam footprints away from land, and the science applications are focused on issues of this regime (e.g. large scale circulation of the global ocean). Salinity will be estimated close to shore but with reduced accuracy. How close to shore the values will be useful and how well corrections can be made for land are important areas of research for Aquarius data.

An important issue in the real world is surface roughness (waves). Compared to a flat surface, roughness causes an increase in brightness temperature. The sensitivity to wave roughness (rate of change in brightness temperature as a function of windspeed) is larger for horizontal polarization than vertical polarization and depends on incidence angle [Lerner and Hollinger, 1977; Camps et al, 2004]. The magnitude of the effect can be comparable to the salinity signal itself. This is presently the most difficult source of error to correct because of the difficulty of characterizing the wave roughened surface. To address this issue, Aquarius includes a scatterometer (radar) that will simultaneously measure the backscatter from the surface at L-band. The scatterometer $(1.26 \mathrm{GHz})$ and the radiometer $(1.413 \mathrm{GHz})$ share the same antenna feeds and the antennas have been 
designed so that the two instruments look at the same pixel with approximately the same $3 \mathrm{db}$ footprint. The instrument timing is designed so that the observations are nearly simultaneous. In 0.72 seconds the radar will have completed 4 measurement cycles of $180 \mathrm{~ms}$, and the radiometers will have completed 6 cycles of $120 \mathrm{~ms}$ (a cycle includes all measurement states and calibration). The algorithm that relates the scatterometer backscatter to the change in radiometric brightness temperature is a research issue. Aircraft experiments are being conducted to develop a baseline algorithm [Wilson et al, 2003] but this will have to be refined once data from space over representative sea states is obtained. Because of the likely need to refine the algorithm based on the scatterometer, Aquarius will also employ an algorithm using roughness estimates based on surface winds obtained from satellite measurements and weather models together with theory and experiments relating wind/waves to changes in brightness temperature at Lband [Dinnat, Le Vine and Abraham, 2008; Yueh et al, 2004; Camps et al, 2004] .

A final issue in the real world is one that shouldn't exist: Interference due to man made signals (Radio Frequency Interference, RFI). Technically, the window at L-band is restricted (no emission), but there are many unintentional sources of contamination. Computers, digital measuring equipment, air traffic control and other radars, etc. The list gets longer as the spectrum on either side of the L-band window gets more and more crowded. The strategy adopted by the Aquarius radiometer is to sample as rapidly as possible. The radiometer will acquire one sample of $9 \mathrm{~ms}$ duration every $10 \mathrm{~ms}$. These samples will then be tested for RFI using a threshold algorithm (Misra and Ruf, 2008). Samples contaminated with RFI will be removed before the final average is computed. The data will be divided into 1.44 second blocks and the average value computed for each block. This average will be used in subsequent processing. The 1.44 second average will be available to the user in the data record together with an indication of how many samples were identified as RFI and removed. The original unprocessed data will be kept in the archive.

\section{AQUARIUS/SAC-D MISSION}


Aquarius is an instrument on the Aquarius/SAC-D mission, a partnership between the National Aeronautics Space Agency (NASA) of the USA and its Argentine counterpart, Comision Nacional de Actividades Espaciales (CONAE). The Aquarius instrument and the launch vehicle are being provided by NASA; the SAC-D spacecraft service platform, several science instruments and mission operations are being provided by CONAE. Table I is a list of the instruments on the observatory. The instruments provided by CONAE include two cameras, the New InfraRed Scanner Technology (NIRST) camera developed jointly with the Canadian Space Agency to detect high temperature events such as forest fires and volcanoes, and a High Sensitivity Optical Camera (HSC) [Sen et al, 2006]. The NIRST has a swath width of $182 \mathrm{~km}$ at the Aquarius altitude which can be scanned over $+/-532 \mathrm{~km}$. This overlaps the innermost Aquarius beam and the NIRST may provide simultaneous SST data in priority areas for comparison with the baseline sources (e.g. GHRSST or NCEP). CONAE is also developing a microwave radiometer (MWR) with the objective of measuring rain, ocean surface wind (speed and direction) and sea-ice. The MWR consists of separate radiometers at 23.8 and $36.5 \mathrm{GHz}$. Each radiometer operates in pushbroom mode with eight beams (i.e. a single reflector with eight feed horns) providing a swath width of $390 \mathrm{~km}$ and a resolution of $50 \mathrm{~km}$. The system at $36.5 \mathrm{GHz}$ is polarimetric ( $\mathrm{V}$ and $\mathrm{H}$ polarization plus the third Stokes parameter) and the radiometer at $23.8 \mathrm{GHz}$ measures vertical polarization only. Each system employs one detector which scans the eight feeds with an estimated sensitivity of $0.5 \mathrm{~K}$. The MWR will be oriented so as to cover the Aquarius swath as shown in Figure 7. This is being done to complement as much as possible the Aquarius measurements (e.g. assist in the development of a rain flag). The $36.5 \mathrm{GHz}$ beams point forward of the Aquarius field of view and the 23.8 point aft. The spacecraft will yaw slightly to guarantee overlap of the FOV of the three instruments. The local incidence angle (i.e. at the surface) for the individual MWR beams is 52-58 degrees.

Also included among the instruments on SAC-D is a GPS atmospheric occultation experiment called ROSA, which will be provided by the Italian Space Agency (ASI), and also an instrument called, CARMEN1, which is contributed by the French Centre National d'Etudes Spatiales (CNES) to measure the radiation and micro-particle 
environment in space. In addition, CONAE is testing a Data Collection System which will provide satellite collection of surface instrumentation over Argentina.

Development of the Aquarius instrument is a partnership between the Goddard Space Flight Center (GSFC) and the Jet Propulsion Laboratory (JPL). GSFC is responsible for the development of the radiometer hardware and processing of the science data, while JPL is responsible for development of the scatterometer, integration and testing of the Aquarius instrument (radiometer plus scatterometer) and has responsibility for pre-launch mission management. GSFC takes over management after launch, including processing of the science data and instrument operations. Once completed, the Aquarius instrument is shipped from JPL to Argentina for integration onto the SAC-D bus. The complete observatory will be sent to Brazil for environmental testing and then to NASA's Vandenberg launch facility for launch (May, 2010). The launch and launch services are managed by NASA's Kennedy Space Center.

After launch, CONAE will provide the ground station and telecommunication services at their ground station and Mission Operations Center (MOC) in Cordoba, Argentina. Mission operations will be controlled at the MOC and ASI will provide additional downlink support for data. Aquarius science telemetry will be separated at the MOC and sent to the Goddard Space Flight Center for processing. The salinity data products will be generated at GSFC. When the processing is finalized the data will be sent to the Physical Oceanography Distributive Active Archive Center (PO.DAAC) at JPL for permanent archiving. Salinity maps and relevant ancillary data will be released to the public from GSFC prior to final archiving.

Table II summarizes the orbit parameters and characteristics of the Aquarius instrument (radiometer and scatterometer). The launch is from NASA's Western Test Range at Vandenberg AFB using a Boeing Delta-II launch vehicle. The observatory will go into a sun-synchronous orbit at an altitude of $657 \mathrm{~km}$, an inclination of 98 degrees and equatorial crossing times of 6 am (descending) and $6 \mathrm{pm}$ (ascending). The orbit is a 7day exact repeat orbit. The Aquarius swath $(390 \mathrm{~km})$ and orbit have been selected so that 
complete global sampling is obtained during each 7-day period. Aquarius salinity data will be released in swath format (Level 2), and in the form of weekly and monthly averaged gridded maps (Level 3). Brightness temperatures and radar cross sections over all surfaces (ocean land and ice) also will be made available in swath format. The swath and orbit has been selected to provide complete geographic coverage and enough data over the ocean in one month to reduce the rms measurement error to less than $0.2 \mathrm{psu}$ on a $150 \mathrm{~km}$ grid scale. See [Lagerloef et al, 2008] for a detailed error budget.

\section{THE AQUARIUS INSTRUMENT}

\section{A. Introduction}

Aquarius has been designed to map the surface salinity field of the global ocean from space. The goal is to monitor the seasonal and interannual variation of the large scale features of the surface salinity field in the open ocean by providing maps on a monthly basis with a spatial resolution of $150 \mathrm{~km}$ and an accuracy of $0.2 \mathrm{psu}$. These are challenging requirements that have led to some unique features. Some of these have already been mentioned: a) The addition of a co-located scatterometer to help provide a correction for roughness; b) The addition of a polarimetric channel (third Stokes parameter) to the radiometer to help correct for Faraday rotation; c) The spacecraft orbit (sun-synchronous with a $6 \mathrm{pm}$ ascending equatorial crossing) to minimize Faraday rotation and with the antennas looking away from the sun toward the nighttime side to minimize contamination by radiation from the sun; and d) An antenna designed to limit side lobes in the direction of rays from the sun. Achieving the accuracy goal ( $0.2 \mathrm{psu})$ requires averaging over one month and to do this requires a highly stable radiometer. The requirements imposed on the Aquarius radiometer are an absolute accuracy better than $0.13 \mathrm{~K}$ maintained over 7 days. To achieve this level of stability, considerable effort was given to the radiometer design [Wilson et al, 2005] and also to the thermal design of the instrument on the spacecraft, specifically to controlling the temperature of the radiometer front end electronics. Detailed descriptions of the instrument can be found in [Le Vine et al, 2007b] and [Pellerano et al, 2006]. An overview of the salient features is presented below. 


\section{B. The Antenna Structure}

Perhaps the most prominent feature of the Aquarius instrument is the antenna, a $2.5-\mathrm{m}$ diameter, offset parabolic reflector with three feed horns. The three beams are arranged to image in pushbroom fashion aligned roughly perpendicular to the spacecraft heading and pointing away from the sun as illustrated in Figure 7. The three beams point at angles of $\theta=25.8,33.8$ and 40.3 degrees with respect to the spacecraft nadir which correspond to local incidence angles at the surface of 28.7, 37.8 and 45.6 degrees, respectively. The resolution of the three radiometer beams (axes of the $3 \mathrm{db}$ ellipse) are: $76 \times 94 \mathrm{~km}$ for the inner beam, $84 \times 120 \mathrm{~km}$ for the middle beam to $96 \times 156 \mathrm{~km}$ for the outer beam (Table II). Together they cover a swath of about $390 \mathrm{~km}$. The three beams do not point exactly across track: the inner and outer beam point slightly forward and the middle beam points slightly aft (Figure 7). The feed for each beam is shared by both the radiometer and scatterometer and is designed so that the two instruments have approximately the same $3 \mathrm{~dB}$ footprint.

Figure 8 is a drawing of the observatory showing how Aquarius will look when deployed in space. The observatory flies with its long axis perpendicular to the plane of the orbit as shown in Figure 7. The dish-like collar at the base of Aquarius where it joins SAC-D is a sun shield which is part of the thermal control for the instrument. The entire structure will also be wrapped in blankets of milar for thermal insulation which is not shown in the drawings or the photograph. The cylindrical structure between the sunshield and solar panels is the SAC-D service platform. The instruments on the bottom, from left to right are the ROSA, the two cameras (NIRST and the HSC), the Data Collection System (DSC) and the MWR. The MWR consists of two reflectors, one for each frequency, with one on each side of the SAC-D. CARMEN-1, the GPS receivers and star trackers are located on the top service platform (same side as the Aquarius reflector).

Figure 9 shows Aquarius in its stowed configuration. On the left is a drawing illustrating Aquarius in its stowed configuration within the Delta-II launch vehicle and on the right is 
a photograph of the actual hardware taken while Aquarius was being prepared for acoustic testing at JPL. The Aquarius reflector is deployed in two steps. The hinge at the reflector-boom junction (Figure 9; right) opens first moving the reflector away from the feeds. This is followed by motion of the boom itself driven by the fold mechanism in the hinge at the base of the boom near the sun shield. In its stowed configuration, the reflector is supported by two pair of struts, one of which can be seen in photograph in Figure 9 in the upper right above the feeds. The feeds will fly uncovered to avoid potential problems (variable loss) associated with radome covers.

An important consideration in the design of Aquarius was thermal control. The requirement is for thermal control to within $<0.1^{\circ} \mathrm{C}$ over 7 days. This is needed for radiometer stability to allow averaging to reduce noise and achieve the final accuracy of $0.2 \mathrm{psu}$. The sun shield is for thermal control. (A shield for RF radiation from the Sun was ruled out because of the large size needed to be effective.) In addition to the passive elements such as the sun shield, the instrument also includes active thermal control of the sensitive parts of the electronics such as the radiometer front end.

\section{The Radiometer}

There are three radiometers in Aquarius, one for each beam. These are Dicke radiometers that use noise injection for calibration. The design is based on research by the GSFC / JPL team to develop a highly stable radiometer system [Wilson et al, 2005; Pellerano et al, 2004]. The radiometer consists of four sections as indicated in the functional diagram (Figure 10): a) The feed assembly which consists of the orthomode transducer (OMT), Calibration Noise Diode (CND) and diplexer; b) Radiometer front end (RFE) which provides the first stage amplification and includes the Dicke load, the reference noise diode (ND), and a hybrid where the two polarization signals are combined to form sum and difference signals (which are combined after detection to compute the third Stokes parameter); c) Radiometer back end (RBE) which provides gain and filtering and includes the detector; d) The digital processing unit (DPU) which provides control and is the interface with the rest of the spacecraft. Each section is 
discussed briefly below. See [Pellerano et al, 2006 and Le Vine et al, 2007b] for more detail and the physical layout of the hardware.

1. Feed Assembly: A prominent element of the feed assembly is the diplexer, a large cavity filter that permits the scatteromter $(1.26 \mathrm{GHz})$ and radiometer $(1.413 \mathrm{GHz})$ to share the same OMT-Feed. This provides adequate separation during scatterometer receive (i.e. the time between pulses). The radiometer is also protected by limiters, and during scatterometer transmit (one millisecond), the radiometer front end is disconnected from the antenna path by switching to the Dicke load. The feed assembly also contains one of two reference noise sources, the CND. The CND is used to calibrate the sum and difference paths out of the hybrid for phase and amplitude balance. This is needed to compute the third Stokes parameter which is done by adding the two signals (sum and difference) after detection.

2. Radiometer Front End (RFE): The RFE includes the second reference noise source (ND) and the Dicke load. The signal from the noise diode ND is alternatively added to the signal from the antenna and Dicke load as part of calibration. The duty cycle has been chosen to optimize calibration and minimize noise (Wilson et al, 2005). There are four outputs from the RFE for each horn: V-pol, H-pol, $(\mathrm{V}+\mathrm{H})$ and $(\mathrm{V}-\mathrm{H})$, the later two provided by a hybrid. The reference sources in the RFE (Dicke load and ND) are at the heart of the radiometer accuracy and stability. Careful attention has been given to temperature control of the RFE ( $0.1 \mathrm{C}$ rms over 7 days) and to stability and knowledge of the noise sources. The radiometer stability requirement of $0.13 \mathrm{~K}$ over 7 days has been demonstrated in prelaunch testing.

3. Radiometer Back End (RBE): The radiometer back end contains additional amplification, band-pass filtering, and the detectors for each channel. It also contains voltage-to-frequency converters that convert each analog output to a series of pulses whose frequency is proportional to the amplitude of the signal. (The frequency is counted and stored digitally in the DPU). Temperature control of the RBE is less critical to the stability of the radiometer because the RBE is located behind all the calibration 
sources and after the first stage gain in the RFE. In the physical layout of the hardware, the RBE has been separated from the RFE to facilitate thermal control of the critical elements in RFE [Le Vine et al, 2007b].

4. Digital Processing Unit (DPU): The final section of the radiometer is the digital processing unit (DPU). The pulse trains from the RBE are counted asynchronously, and the frequency determined, by the DPU. The DPU houses the radiometer controller, collects temperature and housekeeping data, stores data and is the interface with the spacecraft (e.g. for command and control and data downlink).

The radiometer collects data and goes through calibration in a sequence of 12 steps of 10 ms each (120 ms cycles). The first millisecond of each step is blanked to accommodate the scatterometer transmit pulse. Data is collected during the ensuing $9 \mathrm{~ms}$. The first 7 steps are antenna data (antenna temperature) followed by a look at the CND followed by 4 calibration steps (combinations of the Dicke load and/or ND). The calibration data is averaged for $5.76 \mathrm{~s}$ and the radiometer NEDT in $5.76 \mathrm{~s}$ is about $0.08 \mathrm{~K}$. The complete measurement error budget, including radiometer performance and the sampling strategy for achieving $0.2 \mathrm{psu}$, is summarized in Table 2 of Lagerloef et al, 2008.

\section{The Scatterometer}

Although Aquarius has three separate radiometers, one for each feed, it has only one scatterometer. The scatterometer signal is rotated (time shared) among the three feeds and two polarizations. The operation consists of a 6 steps at each the feeds: (1) transmit at H-pol and receiving at V-pol; (2) receive at V-pol (noise only, no transmit); (3) transmit at V-pol and receive at V-pol; (4) transmit at V-pol and receive at H-pol; (5) receive at $\mathrm{H}$-pol (noise only, no transmit); (6) transmit at H-pol and receive at H-pol. This sequence permits the measurement of the backscatter signal at $\mathrm{HV}, \mathrm{VV}$ VH and $\mathrm{HH}$ together with the measurement of the noise (no transmit) in each path. Only the amplitude is measured (no phase information). The scatterometer transmits a $1 \mathrm{~ms}$ pulse with $100 \mathrm{~Hz}$ PRF (pulse repetition frequency) which results in $10 \mathrm{~ms}$ between pulses. During the $9 \mathrm{~ms}$ after the scatterometer transmit operation both the radiometer and the 
scatterometer observe the scene (receive only) and the diplexer insures isolation of the backscatter signal from the radiometer front end. When the scatterometer cycle of measurements at the four polarization steps and two noise-only steps is completed at one beam (feed horn), the scatterometer is switched to the next beam and the cycle is repeated. This is accomplished with a switching network in the scatterometer front end between the scatterometer output and the diplexer. A complete switching cycle over 3 antenna beams takes 18 pulse steps, 12 for echo measurements and 6 for noise only measurements. The time to complete one full scatterometer switching cycle is 0.18 seconds. In $0.72 \mathrm{~s}$, the radiometer will have completed 6 full cycles and the scatterometer 4 full cycles. Data for each of the 4 polarizations will be recorded and stored. Ground processing will compute the total power $(\mathrm{VV}+\mathrm{HH}+\mathrm{VH}+\mathrm{HV})$, which is insensitive to the Faraday rotation, to retrieve the roughness correction for the radiometer. The individual terms can be retrieved using the Faraday rotation angle obtained from the radiometer measurements (i.e. third Stokes parameter).

The scatterometer electronics are divided into five boxes, the Scatterometer Front End (SFE), Scatterometer Back End (SBE), Scatterometer Chirp Generator (SCG), Solid State Power Amplifier (SSPA) and Low Voltage Power Supply (LVPS). The scatterometer is connected to the antenna system through the diplexer and all of the scatterometer electronics with the exception of the diplexer are mounted away from the OMT-feed itself and away from the temperature sensitive elements of the radiometer [ Le Vine et al, 2007b].

The scatterometer front end (SFE) contains the switch, which cycles the output of the single scatterometer among the three feeds and two polarization ports, and also a calibration loop. The output of the switch also contains a load position which can be used for test purposes (i.e. to transmit into the load). The calibration loop employs a coupler to leak a small portion of the transmit energy into the receiver during each transmit pulse. This small leakage signal is proportional to the product of transmit power and receiver gain and is used to calibrate the radar echoes from the surface. The SFE also includes a band pass filter to help suppress RFI. 
The received signal is processed to baseband in the scatterometer back end (SBE). The SBE includes amplifiers, band pass filters and mixers to convert the radar echoes to baseband at $4 \mathrm{MHz}$. The actual power detection is performed in the instrument control and data system (ICDS) where the analog-to-digital (A/D) conversion is done followed by voltage squaring and accumulation. The ICDS also serves as the interface for both the radiometer and scatterometer with the spacecraft bus. To insure that the calibration loop signal is within acceptable dynamic range, the SBE includes a step attenuator following the low noise amplifier. The step attenuator is switched to low insertion loss (about $2 \mathrm{~dB}$ ) during the range gate window to collect echoes and is switched to high insertion loss (about $50 \mathrm{~dB}$ ) during transmit to permit acquisition of data from the calibration loop. The SBE also includes an 8-MHz Stable Local Oscillator (STALO) which together with frequency mutipliers, generates the frequencies needed by the mixers and filters to move signals up and down from baseband and for timing.

The scatterometer chirp generator (generally considered to be part of the SBE) is used to modulate the transmit pulse. The chirp has a bandwidth of $4 \mathrm{MHz}$. Also, part of the scatterometer are the Low Voltage Power Supply (LVPS) which provides power to the Solid State Power Amplifier (SSPA) which powers the transmit pulse. The center frequency (carrier frequency) of the transmit pulse is $1.26 \mathrm{GHz}$.

Thermal control is also part of the calibration strategy for the scatterometer. The thermal design employs passive control to keep the temperature of the electronics within about $1^{\mathrm{o}}$ C. This is expected to keep the change of the total electronics loss to about 0.3 to $0.4 \mathrm{~dB}$. To calibrate the temperature dependence of the various electronics components, prelaunch calibration tests have been conducted to characterize the loss of the calibration loop, step attenuator, beam-select switch and other critical elements as a function of temperature. The goal is to ensure that the residual calibration stability error is much less than $0.1 \mathrm{~dB}$ after the effects of temperature drift have been corrected. 


\section{CONCLUSION}

As of the writing of this manuscript, Aquarius is completing Integration and Testing (I\&T) at JPL. It is scheduled to be shipped to Argentina to begin integration with the SAC-D in May of 2009. Launch is scheduled one year later, May, 2010, at the NASA Western Test Range, Vandenberg Air Force Base, California.

\section{REFERENCES}

Berger, M.; Lopez-Baeza, E.; Wigneron, J.-P.; Calvet, J.-C.; Simmonds, L.; Miller, J.; Finkenzeller, H.; Etcheto, J.; Camps, A.; Font, J.; Wursteisen, P.; Main, B.; Fletcher, P.; Kerr, Y.; Attema, E., "The EuroSTARRS campaign in support of the Soil Moisture and Ocean Salinity mission", Geoscience and Remote Sensing Symposium, 2002. IGARSS '02. 2002 IEEE International, Volume: 2 24-28 June 2002, Page(s): 1152- 1154 vol.2

Bindoff, N.L., J. Willebrand, V. Artale, A, Cazenave, J. Gregory, S. Gulev, K. Hanawa, C. Le Quéré, S. Levitus, Y. Nojiri, C.K. Shum, L.D. Talley and A. Unnikrishnan, 2007: Observations: Oceanic Climate Change and Sea Level. In: Climate Change 2007: The Physical Science Basis. Contribution of Working Group I to the Fourth Assessment Report of the Intergovernmental Panel on Climate Change [Solomon, S., D. Qin, M. Manning, Z. Chen, M. Marquis, K.B. Averyt, M. Tignor and H.L. Miller (eds.)]. Cambridge University Press, Cambridge, United Kingdom and New York, NY, USA. Also available at http://www.ipcc.ch/ipccreports/ar4-wg1.htm

Blanch, S. and A. Aguasca, "Seawater Dielectric Permittivity Model from Measurement at L Band", Proc International Geoscience and Remote Sensing Symposium, IGARSS, Anchorage, AK, 2004.

Blume, H-J. C., B. M. Kendal, and J. C. Fedors, "Measurements of ocean temperature and salinity via microwave radiometry," Boundary Layer Meteorol., vol. 13, pp. 295308, 1978.

Blume, H-J C., B.M. Kendall and J.C. Fedors, "Multifrequency radiometer detection of submarine freshwater along the Puerto Rican Coastline", J. Goephys Res, Vol 86, pp 5283-5291, 1981.

Blume, H-J C. and B.M. Kendall, "Passive Microwave Measurements of Temperature and Salinity in Coastal Zones", IEEE Trans. Geosci Remote Sensing, Vol GE-20, pp 394-404, 1982

Broecker, W.S. “The Great Ocean Conveyer”, Oceanography, Vol 4, pp 79-89, 1991 
Burrage, D.; Wesson, J.; Miller, J., "Deriving Sea Surface Salinity and Density Variations From Satellite and Aircraft Microwave Radiometer Measurements: Application to Coastal Plumes Using STARRS", Geoscience and Remote Sensing, IEEE Transactions on, Vol 46 Issue: 3 March 2008, Page(s): 765-785

DOI 10.1109/TGRS.2007.915404

Camps, A.; Font, J.; Vall-llossera, M.; et al., "The WISE 2000 and 2001 field experiments in support of the SMOS mission: sea surface L-band brightness temperature observations and their application to sea surface salinity retrieval", IEEE Trans. Geosci. Remote Sens., Vol. 42, no. 4, pp.804 - 823, April 2004.

Dickson, R.R., R. Meincke, S.-A. Malmberg and J.J. Lee, "The 'Great Salinity Anomaly' in tdhe Northern North Atlantic, 1968-1982”, Prog. Oceanography, Vol 20, pp 103-151, 1988 .

Dinnat, E.P. and D. M. Le Vine, "Impact of Sun Glint on Salinity Remote Sensing: An Example with the Aquarius Radiometer", IEEE Trans. Geosci. Remote Sens., Vol. 46, no. 10, pp. 3137-3150, October, 2008.

Dinnat, E.P. Le Vine, D.M. Abraham, S., "L-band radiometry and reflection of the galaxy by a rough ocean surface.", Proceedings MICRORAD 2008, Firenze, Italy, pp: 1 - 4, 11-14 March 2008.

Dinnat, E.P., S. Abraham, D. M. Le Vine, P. de Matthaeis and S.D. Jacob, "Effect of Emission from the Moon on Remote Sensing of Sea Surface Salinity: An Example with the Aquarius Radiometer", IEEE Trans. Geosci. Remote Sens., Vol. 47, no. 5, pp. 239243, April, 2009.

Donlon, C., I. Robinson, K. Casey, J. Vasquez, et al., "The GODAE high resolution sea surface temperature pilot project (GHRSST-pp)", Bulletin of the American Meteorological Society, Vol 88 (no 8), pp 1197-1213, 2007.

Droppelman, J.D., R. A. Mennella and D.E. Evans, "An Airborne Measuremtn of the Salinity Variations of the Mississippi River Outflow”, J. Geophys. Res, Vol 75, pp 59095913, 1970.

Ellison, W., A. Balana, G. Delbos, K. Lamkaouchi, L. Eymard, C. Guillou and C. Prigent, "Study and measurements of the dielectric properties of sea water", Tech report 11197/94/NL/CN, European Space Agency, Paris, 1996.

Ellison, W., A. Balana, G. Delbos, K. Lamkaouchi, L. Eymard, C. Guillou and C. Prigent, "New permittivity measurements of sea water", Radio Science, Vol 33, pp 639648, 1998. 
Font, J.,A. Camps, A. Borges, M. Martin-Neira, Y. Kerr, A. Hahne, S. Macklenburg, "SMOS: The Challenging Sea Surface Salinity Measurement from Space", IEEE Proc. Vol xx, pp. yy, 2009.

Gentemann, C.L, F.J. Wentz, C.M. Mears, and D.K. Smith., "In-situ validation of TRMM microwave sea surface temperatures", J. Geophys. Res.,Vol.109, no. C4, pp. 15, April 2004.

Johnson, E. S., G. S. E. Lagerloef, J. T. Gunn, and F. Bonjean, "Surface salinity advection in the tropical oceans compared to atmospheric freshwater forcing: a trial balance", J. Geophys. Res., doi: 10.1029/2001JC001122, Vol.107, no.C12: SRF15-1-11 15 December 2002.

Kainulainen, J.; Rautiainen, K.; Tauriainen, S.; Auer, T.; Kettunen, J.; Hallikainen, M., "First 2-D Interferometric Radiometer Imaging of the Earth From an Aircraft", Geoscience and Remote Sensing Letters, IEEE, Volume: 4 Issue: 2 April 2007 Page(s): 241-245, DOI 10.1109/LGRS.2006.890553

Kendall, B. M. and J.O. Blanton, "Microwave Radiometer Measurement of Tidally Induced Salinity Changes off the Georgia Coast", J. Geophys. Res. Vol 86, pp 64356441,1981

Klein, L.A. and C.T. Swift, "An improved model for the dielectric constant of sea water at microwave frequencies", IEEE Trans. Antennas and Propag., Vol. AP-25, no. 1, pp. 104-111, January 1977.

Koblinsky, C.J., P. Hildebrand, D. Le Vine and F. Pellerano, "Sea surface salinity from space: Science goals and measurement approach", Radio Science, Vol. 38 no. 4, 8024, doi:10.1029/2001RS002584, March 2003.

Kraus, J.D., Radio Astronomy, McGraw-Hill, 1966, Section 6.2.

Lagerloef, G.S.E, C. Swift, D. Le Vine, "Sea surface salinity: The next remote sensing challenge", Oceanogr. Vol. 8,no. 2, pp. 44-50, 1995.

Lagerloef, G, F. R. Colomb, D. Le Vine, F. Wentz, S. Yueh, C. Ruf, J. Lilly, J. Gunn, Y. Chao, A. deCharon and C. Swift, "The Aquarius/SAC-D mission - Designed to Meet the Salinity Remote Sensing Challenge”, Oceanography Magazine, Vol 21 (no 1), pp 68-81, March, 2008.

Lang, R.H., Y. Tarkocin, C. Utku and D.M. Le Vine, "Accurate L-Band Dielectric Constant Measurements of Seawater", Proc. Specialist Meeting on Microwave Radiometry and Remote Sensing, Microrad2008, Florence, Italy, February, 2008.

Lang, R.H., H. Ghaemi, Y. Tarkocin, C. Utku and D.M. Le Vine, "Measurement of the Dielectric Constant of Seawater at L-Band: Techniques and Measurements", USNC/URSI National Radio Science Meeting, Boulder, CO, January, 2009. 
Lerner, R.M. and J.P. Hollinger, "Analysis of $1.4 \mathrm{GHz}$ Radiometric Measurements from Skylab”, Remote Sensing of Environment, Vol 6, pp 251-269, 1977.

Le Vine, D.M., M. Kao, R. Garvine and T. Sanders, "Remote sensing of ocean salinity: Results from the Delaware Coastal Current experiment", J. Atmos. Oceanic Tech. Vol.15, pp. 1478-1484, December 1998.

Le Vine, D. M., "Synthetic Aperture Radiometer Systems", IEEE Trans Microwave Theory and Techniques, Vol 47 (No. 12), pp 2228-2236, December, 1999.

Le Vine, D.M., C.T. Swift and M. Haken, "Development of the Syntheitic Aperture Radiometer, ESTAR", IEEE Trans. Geoscience and Remote Sensing, Vol 39, No 1, pp 199-202, January, 2001.

Le Vine, D.M. and S. Abraham, "The effect of the ionosphere on remote sensing of sea surface salinity from space: Absorption and emission at L-band", IEEE Trans. Geosci. Remote Sens., Vol. 40, no. 4, pp. 771-782, April 2002.

Le Vine, D.M. and S. Abraham, "Galactic Noise and Passive Microwave Remote Sensing from Space at L-Band”, IEEE Trans. Geosci. Remote Sens., Vol. 42, no. 1, pp. 119-129, January, 2004.

Le Vine, D.M., S. Abraham, F. Wentz, G.S.E. Lagerloef, "Impact of the Sun on remote sensing of sea surface salinity from space”, Proc. Internat. Geosci. \& Remote Sens. Sympos, IGARSS05, Vol 1, doi: 10.1109/IGARSS.2005.1526164, Seoul, S. Korea, July 2005.

Le Vine, D.M., S. D. Jacob, E.P. Dinnat, P. de Matthaeis and S. Abraham, "The Influence of Antenna Pattern on Faraday Rotation in Remote Sensing at L-Band", IEEE Trans. Geoscience and Remote Sensing, Vol 45, No. 9, September, 2007.

Le Vine, D.M., G.S.E. Lagerloef, F. R. Colomb, S. H. Yueh, F. A. Pellerano, “Aquarius: An Instrument to Monitor Sea Surface Salinity from Space”, IEEE Trans. Geosci. Remote Sens., Vol. 45, no. 7, pp. 2040-2050, July, 2007 b.

Le Vine, D.M. and C. Utku, "Comments on Modified Stokes Parameters", Accepted for publication, IEEE Trans. Geoscience and Remote Sensing, January, 2009.

Liebe, H.J., P.W. Rosenkranz and G.A. Hufford, "Atmospheric 60-GHz Oxygen Spectrum: New Laboratory Measurements and Line Parameters", J. Quantitiative Spectroscopy and Radiative Transfer, Vol 48, pp 629-643, 1992.

Lukas, R. and E.R. Lindstrom, "The mixed layer of the Western Equatorial Pacific Ocean”, J. Geophys. Res., 96 (suppl.), pp. 3343-3357, February 1991. 
Lukas, R. and F. Santiago-Mundujano, "Interannual to Interdecadal Salinity Variations Observed Near Hawaii: Local and Remote Forcing by Surface Freshwater Fluxes", Oceanography, vol 21(1), pp 46-55, March,2008.

Meissner, T. and F. J. Wentz, "The complex dielectric constant of pure and sea water from Microwave Satellite Observations", IEEE Trans Geoscience and Remote Sensing, Vol 42, No 9, pp 1836-1849, September, 2004.

Miller, J., M.A. Goodberlet and J.B. Zaitzeff, "Airborne salinity mapper makes debut in coastal zone”, EOS Trans. AGU, Vol 79, pp 173-177, 1998.

Miller, J.L.; Payne, S., "Remote sensing of coastal salinity: naval needs and developing capability", Geoscience and Remote Sensing Symposium, 2000. Proceedings. IGARSS 2000. IEEE 2000 International, vol 6, pp: 2534-2536, DOI

10.1109/IGARSS.2000.859631.

Sprintall, J. and M. Tomzcak, "Evidence of the barrier layer in the surface layer of the tropics”, J. Geophys. Res., Vol. 97, no C5, pp. 7305-7316, May 1992.

Misra, S. and C.S. Ruf, "Detection of Radio-Frequency Interference for the Aquarius Radiometer”, Geoscience and Remote Sensing, IEEE Transactions on, Vol. 46 Issue: 10 Part 2, pp 3123-3128, Oct. 2008, DOI 10.1109/TGRS.2008.920371

Oceanography Magazine, Special Issue on Ocean Salinity, Vol 21 (no 1), pp 68-81, March, 2008.

Peake, W.H., "Interaction of electromagnetic waves with some natural surfaces", IRE Trans. Antennas and Propagation, Vol AP-7, pp. S324-S329, 1959.

Pellerano, F.A.; Horgan, K.A.; Wilson, W.J.; Tanner, A.B., "Development of a highstability microstrip-based L-band radiometer for ocean salinity measurements", Geoscience and Remote Sensing Symposium, 2004. IGARSS '04. Proceedings. 2004 IEEE International, Vol 2, 20-24 Sept. 2004, pp: 774-776.

Pellerano, F.A.; Piepmeier, J.; Triesky, M.; Horgan, K.; Forgione, J.; Caldwell, J.; Wilson, W.J.; Yueh, S.; Spencer, M.; McWatters, D.; Freedman, A., “The Aquarius Ocean Salinity Mission High Stability L-band Radiometer", Geoscience and Remote Sensing Symposium, 2006. IGARSS 2006. IEEE International Conference on, July 31 2006-Aug. 4 2006, Page(s): 1681-1684.

Plonsey, R. and R.E. Collin, Principles and Applications of Electromagnetic Fields, McGraw-Hill, 1961, Section 10.2.

Reul, N., J. Tenerelli, B. Chapron and P. Waldteufel, "Modeling Sun Glitter at L-Band for Sea Surface Salinity Remote Sensing With SMOS”, IEEE Trans. Geoscience and Remote Sensing, Vol 45, No. 7, July, 2007. 
Sen, A. Y. Kim, D. Caruso, G. Lagerloef, R. Colomb, D. Le Vine and S. Yueh, "Aquarius/SAC-D Mission Overview", Proc. SPIE Conf. "Sensors, Systems, and NextGeneration Satellites X”, Stockholm, Sweden, Proc. of SPIE, Vol. 6361, 63610I, doi: 10.1117/12.691981, September 2006

Schmitt, R.W., "The ocean freshwater cycle", JSC Ocean Observing System Development Panel, Texas A\&M University, College Station, Texas, 40pp, 1994.

Sprintall, J. and M. Tomzcak, "Evidence of the barrier layer in the surface layer of the tropics”, J. Geophys. Res., Vol. 97, no C5, pp. 7305-7316, May 1992.

Stogryn, A., "Equation for calculating the dielectric constant of saline water", IEEE Trans. Microwave Theory and Techniques, Vol 19, pp. 733-736, 1971.

Stogryn, A., P.H. T. Bull, K. Rubayi and S. Iravanchy, "The microwave dielectric properties of sea and fresh water", Tech report, GenCorp Aerojet, Sacramento, CA, 1995.

Stogryn, A., "Equations for the permittivity of sea water", Tech report, GenCorp Aerojet, Sacramento, CA, 1997.

Swift, C.T. and R. E. McIntosh, "Considerations for microwave remote sensing of oceansurface salinity," IEEE Trans. Geosci. Remote Sensing, vol. GE-21, pp. 480-491, 1983.

Thompson, A.R., J. M. Moran, and G. W. Swenson, Interferometry and Synthesis in Radio Astronomy. New York: Wiley, Chapter 13, 1986.

Ulaby, F.T., R. K. Moore and A.K. Fung, Microwave Remote Sensing, Addison-Wesley Publishing Co, 1981.

Wilson, W.J.; Yueh, S.H.; Dinardo, S.J.; Chazanoff, S.L.; Kitiyakara, A.; Li, F.K.; Y. Rahmat-Samii, "Passive active L- and S-band (PALS) microwave sensor for ocean salinity and soil moisture measurements," IEEE Trans. Geosci and Remote Sensing, Vol. 39, no. 5, pp. 1039-1048, May 2001.

Wilson, W.J.; Yueh, S.H.; Dinardo, S.; Yi Chao; Fuk Li, "Precision ocean salinity measurements using the Passive Active L/S-band aircraft instrument", Geoscience and Remote Sensing Symposium, 2003. IGARSS '03. Proceedings. 2003 IEEE International Volume: 4, Page(s): 2792- 2794, DOI 10.1109/IGARSS.2003.1294587, 21-25 July 2003

Wilson, W. J., Tanner, A., Pellerano, F., and Horgan, K., "Ultrastable radiometers for future sea surface salinity missions", Jet Propulsion Laboratory Internal Report D-31794, April 2005. 
Wolleben, M., T. L. Landecker, W. Reich, and R.Wielebinski, “An absolutely calibrated survey of polarized emission from the northern sky at $1.4 \mathrm{GHz}$ observations and data reduction," Astronomy \& Astrophysics, vol. 448, pp. 411-424, 2006.

Yueh, S.H., "Estimates of Faraday rotation with passive microwave polarimetry for microwave remote sensing of Earth surfaces", IEEE Trans. Geosci Remote Sens., Vol 38, no. 5, pp 2434-24-38, September 2000.

Yueh, S.H., R. West, W.J. Wilson, F.K. Li, E.G. Njoku, and Y. Rahmat-Samii, "Error sources and feasibility for microwave remote sensing of ocean surface salinity", IEEE Trans. Geosci and Remote Sensing, Vol 39, no. 5, pp 1049-1059, May 2001.

Yueh, S.H., "Microwave remote sensing modeling of ocean surface salinity and winds using an empirical sea surface spectrum", Geoscience and Remote Sensing Symposium, 2004. IGARSS '04. Proceedings. 2004 IEEE International, Vol: 2 , Page(s): 1358- 1361, Digital Object Identifier 10.1109/IGARSS.2004.1368670, 20-24 Sept. 2004

\section{Figure Captions}

Figure 1: The geometry for microwave remote sensing of the ocean.

Figure 2: The model function relating the brightness temperature to the physical temperature of sea water. The data presented are for normal incidence $(\theta=0)$ and were computed using the dielectric constant reported by Klein and Swift [1977].

Figure 3: The sensitivity to changes in brightness temperature for nadir (broken curve) and at 40 degrees (solid curves). The calculations are for a surface with SSS $=35$ psu and $\mathrm{SST}=20 \mathrm{C}$.

Figure 4: Top: Ship tracks and derived salinity map. Bottom: Comparison of salinity from the R/V Henlopen (solid) and derived from ESTAR measurements (broken) along a track where the aircraft flew over the ship.

Figure 5: Comparison of the salinity maps derived from aircraft remote sensing with ESTAR (left) and from the shipborne thermosalinographs (right). The ships took 3 days to make the map whereas the aircraft took 3 hours which accounts for some of the differences.

Figure 6: Schematic indicating the dominant factors at play in remote sensing of ocean salinity from space at L-band. "Galactic, Cosmic" represents the contribution from the cosmic background and a multitude of sources outside the solar system.

Figure 7: The remote sensing geometry. The x-axis is in the direction of motion, the zaxis points to nadir and the y-axis points away from the Sun. The Aquarius instruments look to the night time side of the orbit, roughly perpendicular to the flight direction and 
covering a swath of $380 \mathrm{~km}$. The Microwave Radiometer (MWR) is an 8 beam pushbroom radiometer. The two MWR footprints are aligned to cover the same swath as Aquarius.

Figure 8: Schematic showing the Aquarius/SAC-D observatory with Aquarius in its deployed configuration. Aquarius ends at the sun shield. To the right is the SAC-D service platform ending with the solar panels. The reflector is $2.5 \mathrm{~m}$ in diameter.

Figure 9: (Left) Drawing showing Aquarius in its stowed position inside the Delta-II launch shroud and (right) the actual flight hardware in its stowed configuration during acoustic testing at JPL. Aquarius mates to SAC -D along a ring just barely visible at the base of the sun shield.

Figure 10: Radiometer schematic showing the major steps in processing. 
TABLE I

Aquarius / SAC-D Instruments

\begin{tabular}{|c|c|c|c|c|}
\hline Instrument & Objective & Description & Resolution & Source \\
\hline Aquarius & $\begin{array}{l}\text { Sea Surface Salinity } \\
\text { (SSS) }\end{array}$ & $\begin{array}{l}\text { Radiometer }(1.4 \mathrm{GHz}) \\
\text { Radar }(1.26 \mathrm{GHz})\end{array}$ & $\begin{array}{l}76 \times 94 \mathrm{~km} \\
84 \times 120 \mathrm{~km} \\
96 \times 156 \mathrm{~km}\end{array}$ & NASA \\
\hline $\begin{array}{l}\text { MWR: Microwave } \\
\text { Radiometer }\end{array}$ & $\begin{array}{l}\text { Precipitation; Wind } \\
\text { speed; sea ice }\end{array}$ & $\begin{array}{l}23.8 \text { and } 37 \mathrm{GHz} \\
390 \mathrm{~km} \text { swath }\end{array}$ & $40 \mathrm{~km}$ & CONAE \\
\hline $\begin{array}{l}\text { NIRST: New Infrared } \\
\text { Sensor Technology }\end{array}$ & $\begin{array}{l}\text { Fires, Sea Surface } \\
\text { Temp }\end{array}$ & $\begin{array}{l}3.8,10.7,11.7 \mu \mathrm{m} \\
180 \mathrm{~km} \text { swath }\end{array}$ & $350 \mathrm{~m}$ & CONAE \\
\hline $\begin{array}{l}\text { HSC: High Sensitivity } \\
\text { Camera }\end{array}$ & $\begin{array}{l}\text { Urban lights; Fire } \\
\text { detection }\end{array}$ & $\begin{array}{l}450-900 \mu \mathrm{m} \\
700 \mathrm{~km} \text { swath }\end{array}$ & $200-300 \mathrm{~m}$ & CONAE \\
\hline $\begin{array}{l}\text { DCS: Data collection } \\
\text { System }\end{array}$ & $\begin{array}{l}\text { Environmental data } \\
\text { collection }\end{array}$ & $401.55 \mathrm{MHz}$ uplink & $\begin{array}{l}2 \text { contact/day } \\
200 \text { platforms }\end{array}$ & CONAE \\
\hline $\begin{array}{l}\text { ROSA: Radio } \\
\text { Occultation Sounder for } \\
\text { Atmosphere }\end{array}$ & $\begin{array}{l}\text { Atmospheric Temp } \\
\text { \& humidity profiles }\end{array}$ & GPS occultation & $300 \mathrm{~km}$ & ASI (Italy) \\
\hline $\begin{array}{l}\text { CARMEN 1: ICARE } \\
\text { \& SODAD }\end{array}$ & $\begin{array}{l}\text { Effects of Radiation } \\
\text { space } \mu \text {-particles \& } \\
\text { debris }\end{array}$ & $\begin{array}{l}\text { Si/LI detectors and } \\
\text { SMOS sensors }\end{array}$ & & $\begin{array}{l}\text { CNES } \\
\text { (France) }\end{array}$ \\
\hline
\end{tabular}

TABLE II

Parameters of the Aquarius Instrument

\begin{tabular}{|c|c|c|c|}
\hline \multicolumn{2}{|l|}{ Orbit } & \multicolumn{2}{|c|}{ Antenna } \\
\hline Altitude & $657 \mathrm{~km}$ & Main Reflector & $2.5 \mathrm{~m}$ offset \\
\hline Sun-synchronous & $6 \mathrm{pm}$ ascend & Beam look angles (deg) & $25.8,33.8,40.3$ \\
\hline Inclination & $98 \mathrm{deg}$ & Local incidence (deg) & $28.7,37.8,45.6$ \\
\hline Coverage & 7 day global & Resolution & $76 \times 94,84 \times 120$ \\
\hline Swath & $390 \mathrm{~km}$ & & $96 \times 156 \mathrm{~km}$ \\
\hline \multicolumn{2}{|c|}{ Radiometer } & \multicolumn{2}{|c|}{ Scatterometer } \\
\hline Frequency & $1.413 \mathrm{GHz}$ & Frequency & $1.26 \mathrm{GHz}$ \\
\hline Polarization & Polarimetric & Polarization & $\mathrm{HH}, \mathrm{VH}, \mathrm{HV}$, \\
\hline Sample time & $10 \mathrm{~ms}$ & & VV \\
\hline Integration time/sample & $9 \mathrm{~ms}$ & PRF & $100 \mathrm{~Hz}$ \\
\hline NEDT (5.76 seconds) & $0.06 \mathrm{~K}$ & Pulse width & $0.98 \mathrm{~ms}$ \\
\hline Calibration Stability & $0.13 \mathrm{~K}$ & Calibration & $0.1 \mathrm{~dB}$ \\
\hline
\end{tabular}



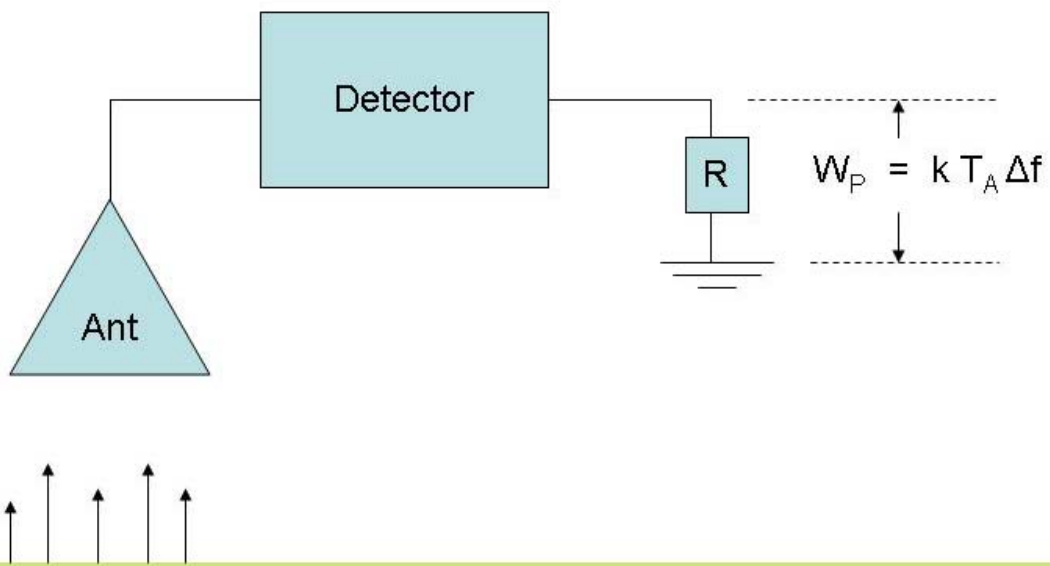

$\mathrm{B}=2 \mathrm{k} \mathrm{T}_{\mathrm{B}} / \lambda^{2}$

Ocean

$$
\mathrm{T}_{\mathrm{B}}=\mathrm{e} \mathrm{T}_{\text {phys }}
$$

Figure 1: The geometry for microwave remote sensing of the ocean. 


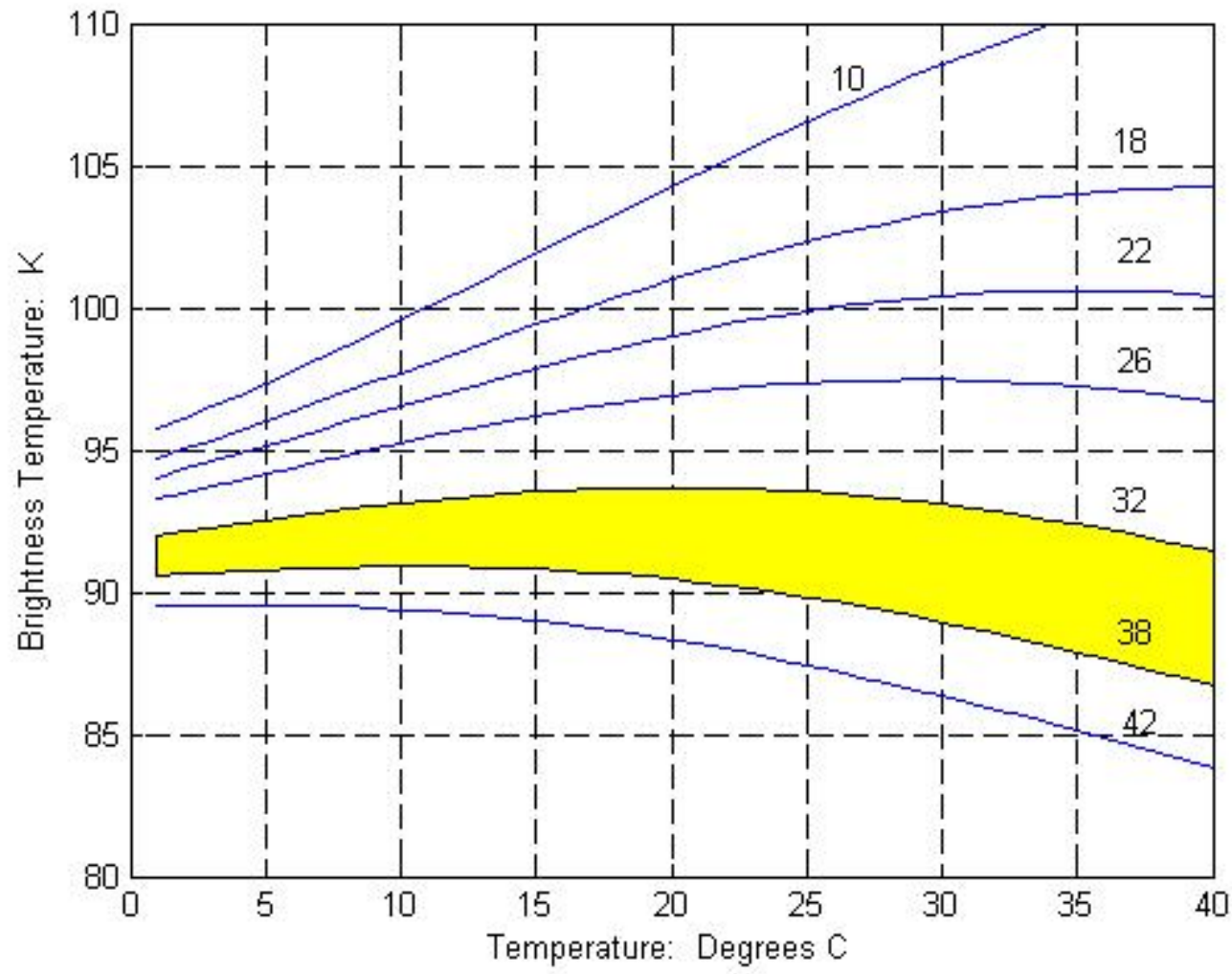

Figure 2: The model function relating the brightness temperature to the physical temperature of sea water. The data presented are for normal incidence $(\theta=0)$ and were computed using the dielectric constant reported by Klein and Swift [1977]. 


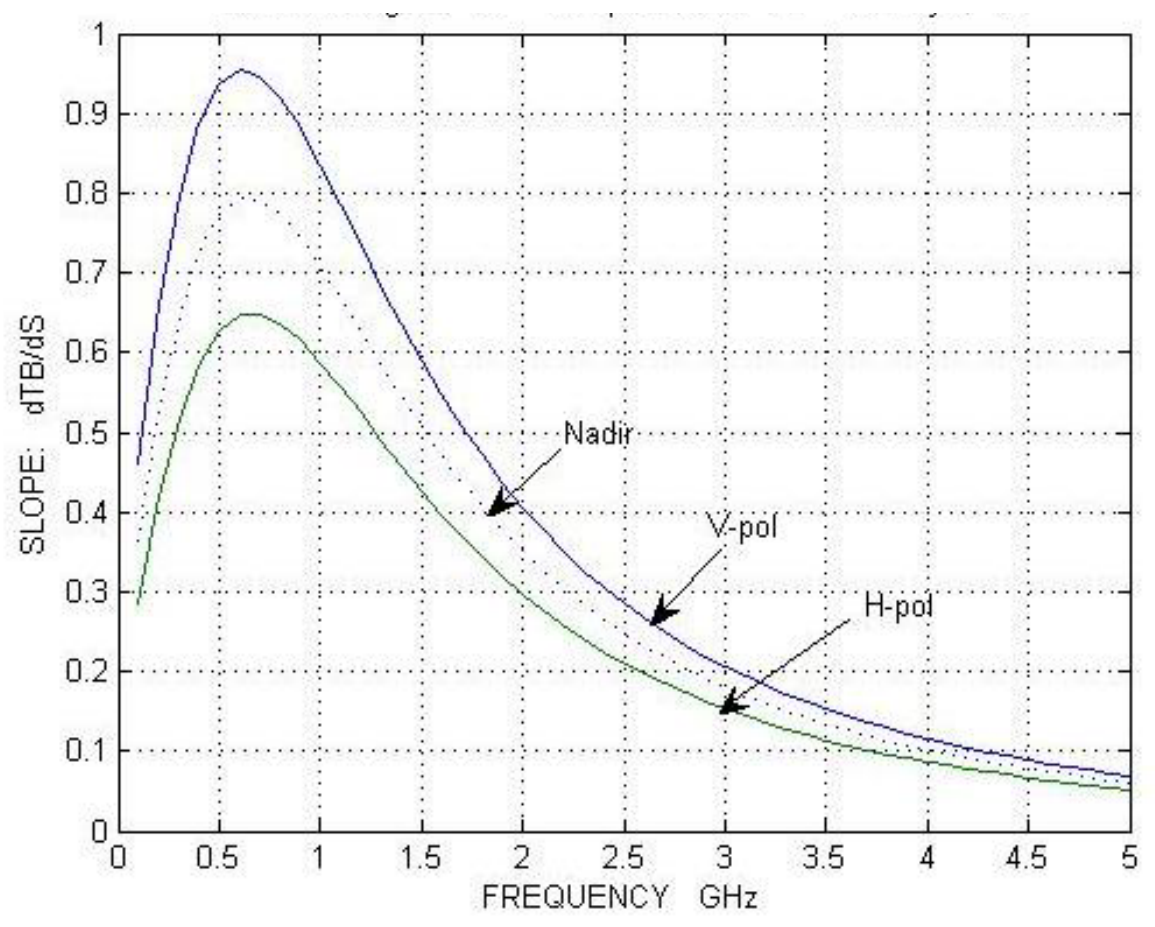

Figure 3: The sensitivity to changes in brightness temperature for nadir (broken curve) and at 40 degrees (solid curves). The calculations are for a surface with SSS $=35 \mathrm{psu}$ and $\mathrm{SST}=20 \mathrm{C}$. 

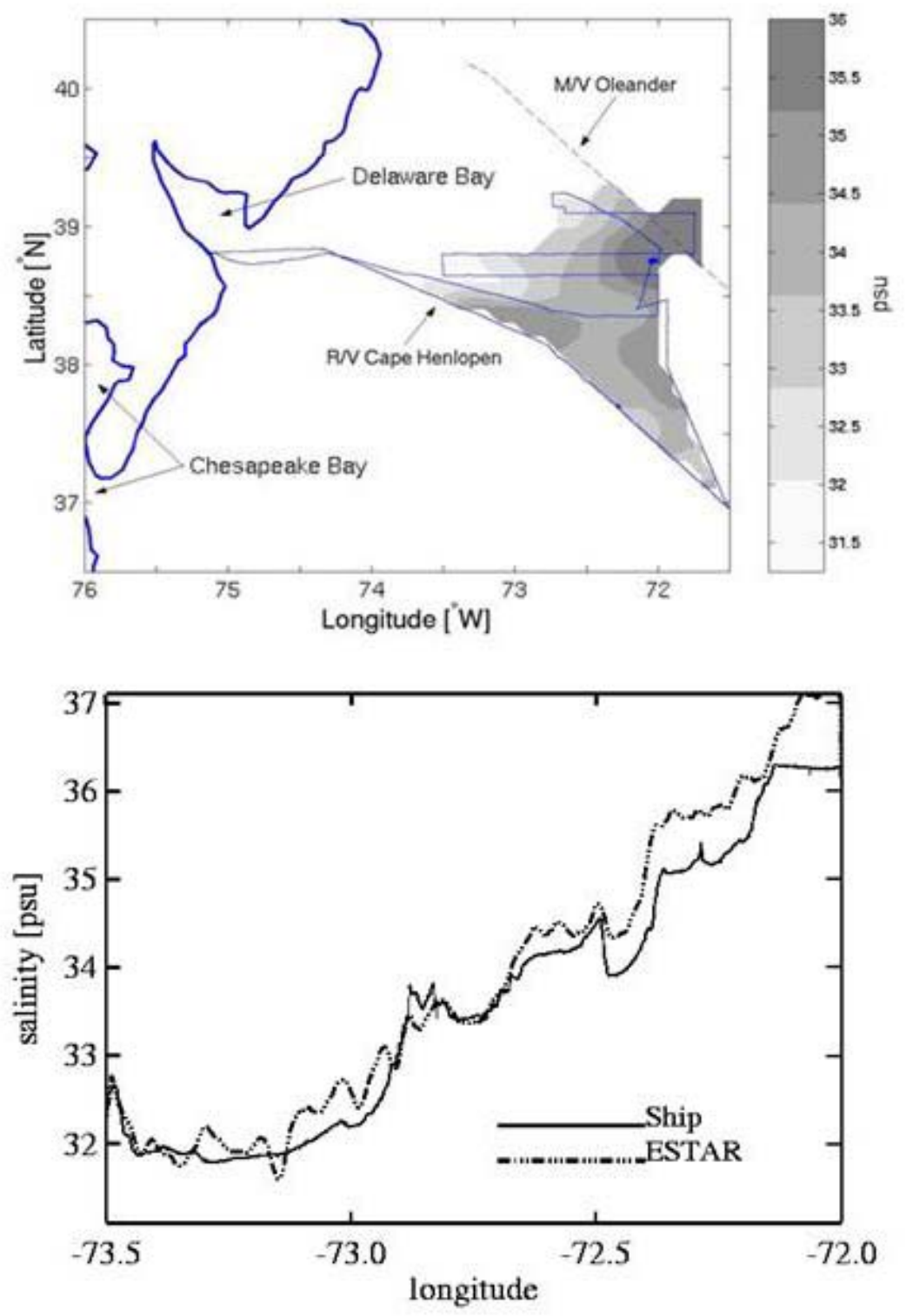

Figure 4: Top: Ship tracks and derived salinity map. Bottom: Comparison of salinity from the R/V Henlopen (solid) and derived from ESTAR measurements (broken) along a track where the aircraft flew over the ship. 

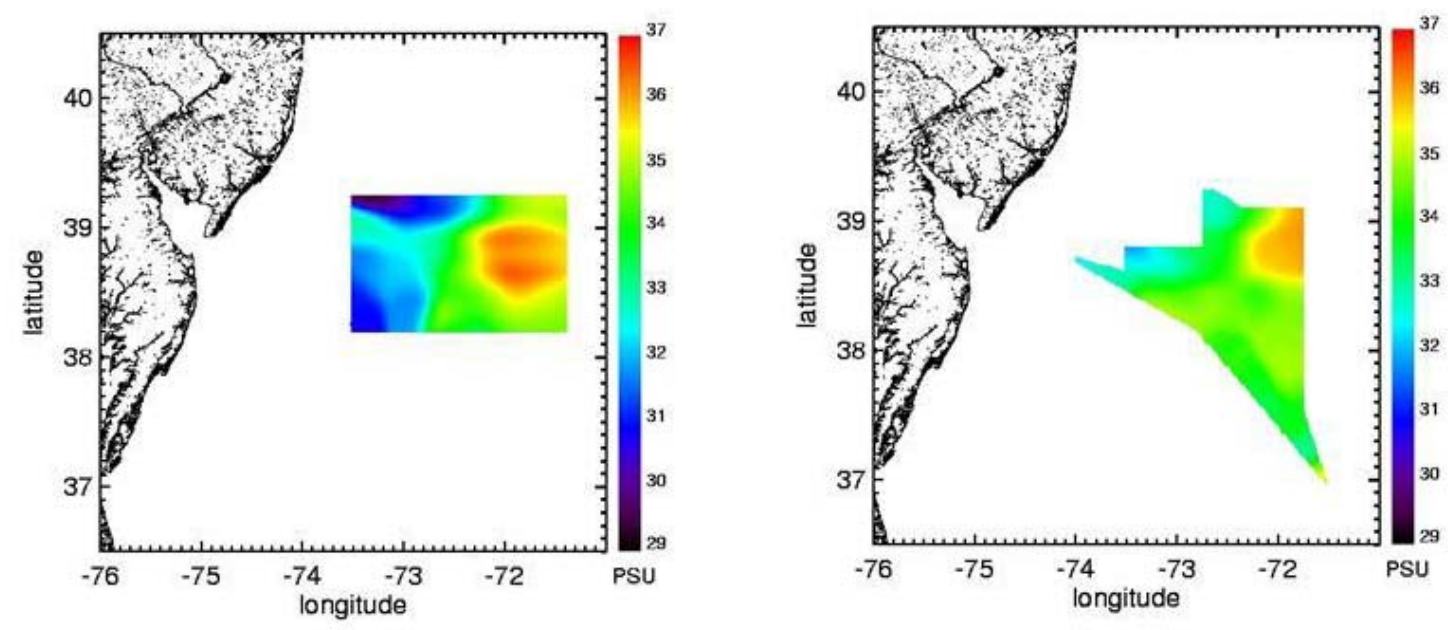

Figure 5: Comparison of the salinity maps derived from aircraft remote sensing with ESTAR (left) and from the shipborne thermosalinographs (right). The ships took 3 days to make the map whereas the aircraft took 3 hours which accounts for some of the differences. 


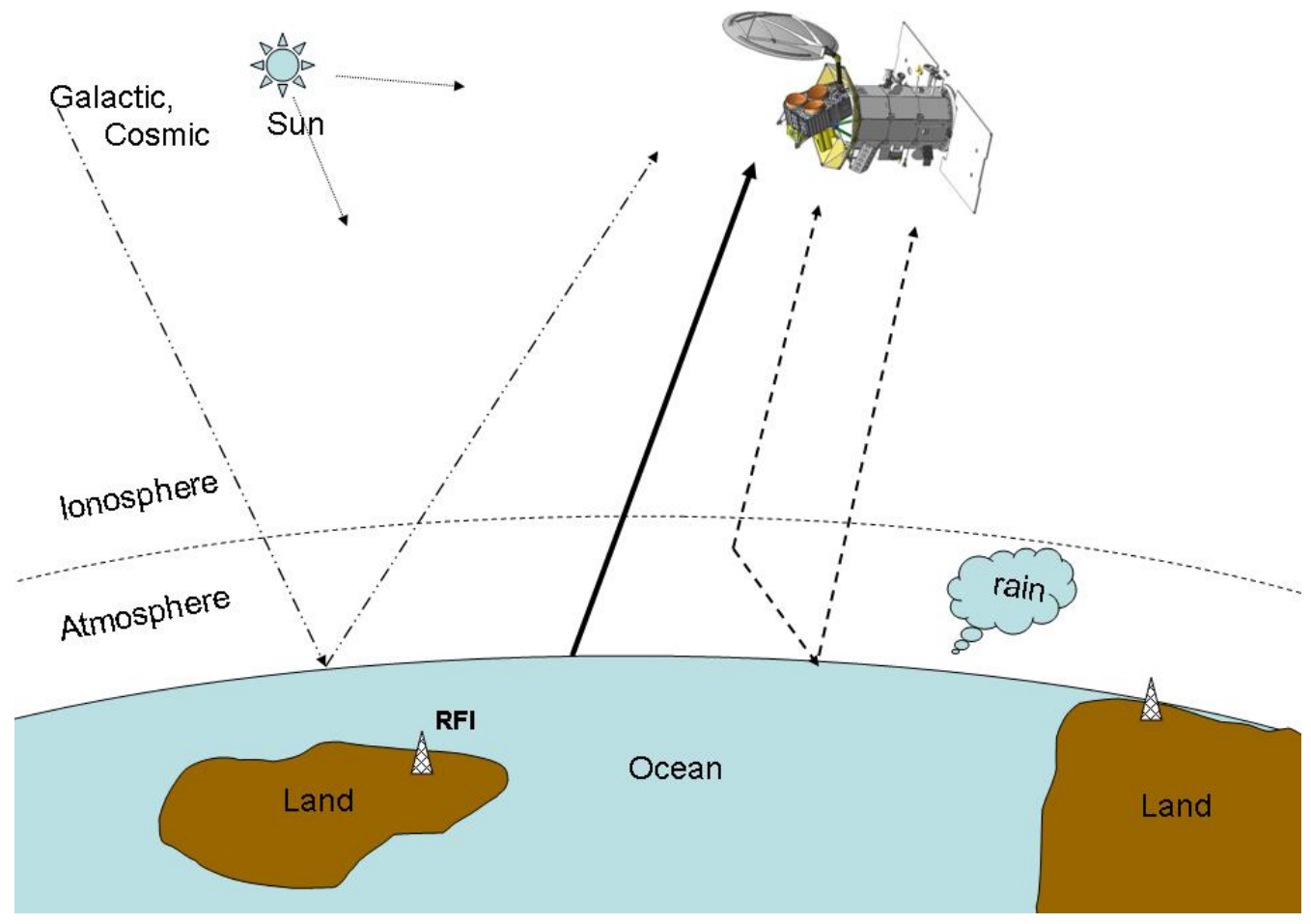

Figure 6: Schematic indicating the dominant factors at play in remote sensing of ocean salinity from space at L-band. "Galactic, Cosmic" represents the contribution from the cosmic background and a multitude of sources outside the solar system. 


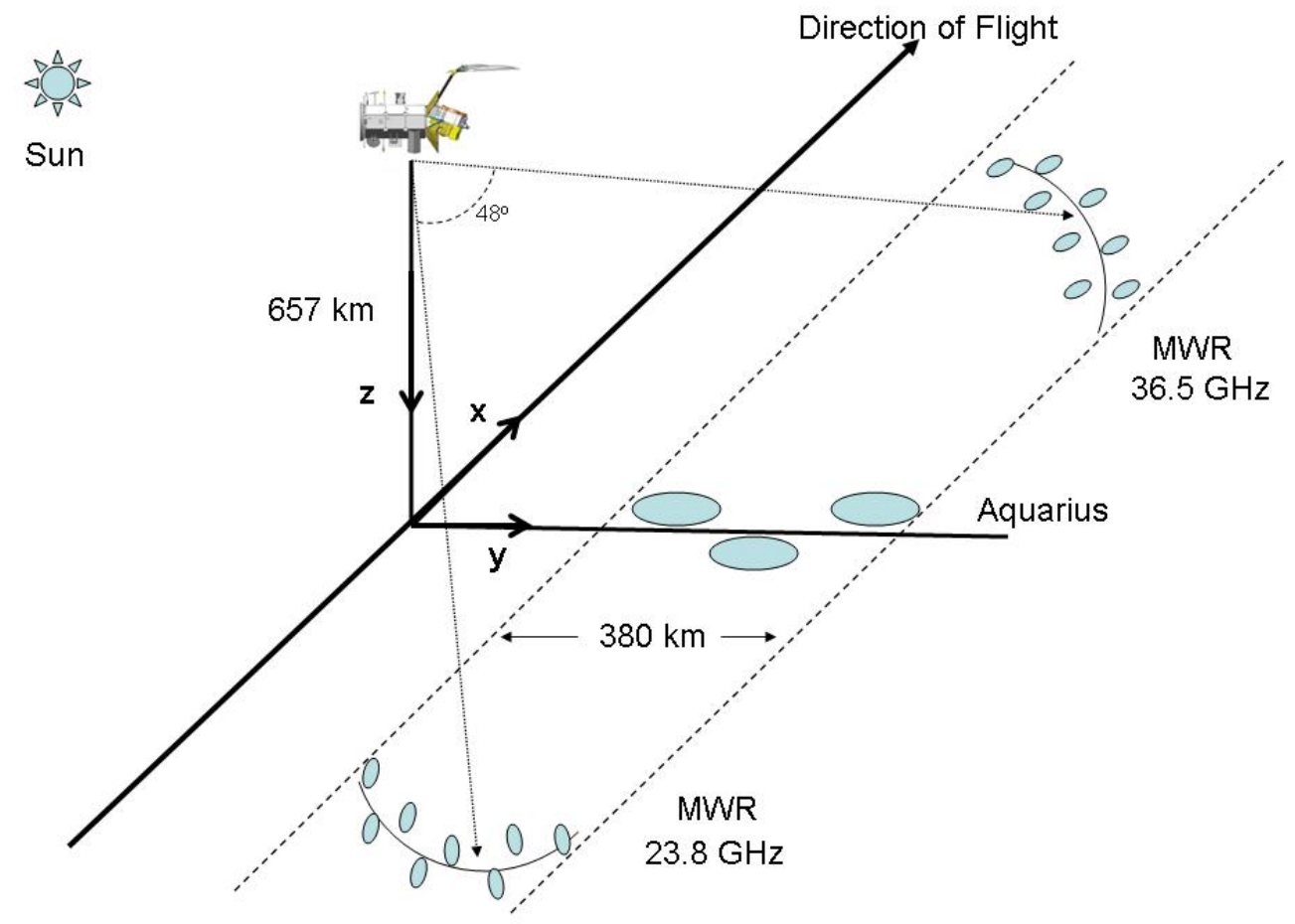

Figure 7: The remote sensing geometry. The $\mathrm{x}$-axis is in the direction of motion, the z-axis points to nadir and the y-axis points away from the Sun. The Aquarius instruments look to the night time side of the orbit, roughly perpendicular to the flight direction and covering a swath of $380 \mathrm{~km}$. The Microwave Radiometer (MWR) is an 8 beam pushbroom radiometer. The two MWR footprints are aligned to cover the same swath as Aquarius. 


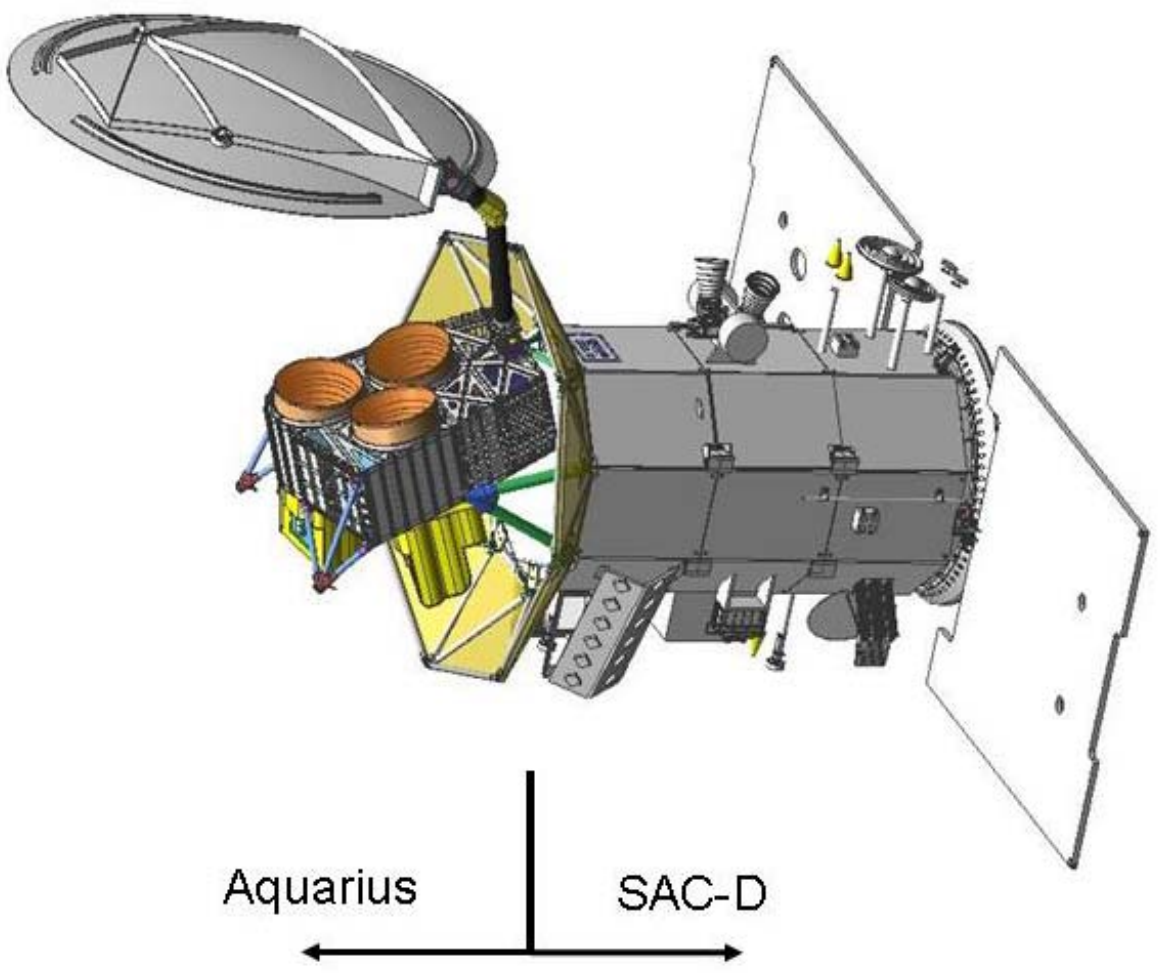

Figure 8: Schematic showing the Aquarius/SAC-D observatory with Aquarius in its deployed configuration. Aquarius ends at the sun shield. To the right is the SAC-D service platform ending with the solar panels. The reflector is $2.5 \mathrm{~m}$ in diameter. 

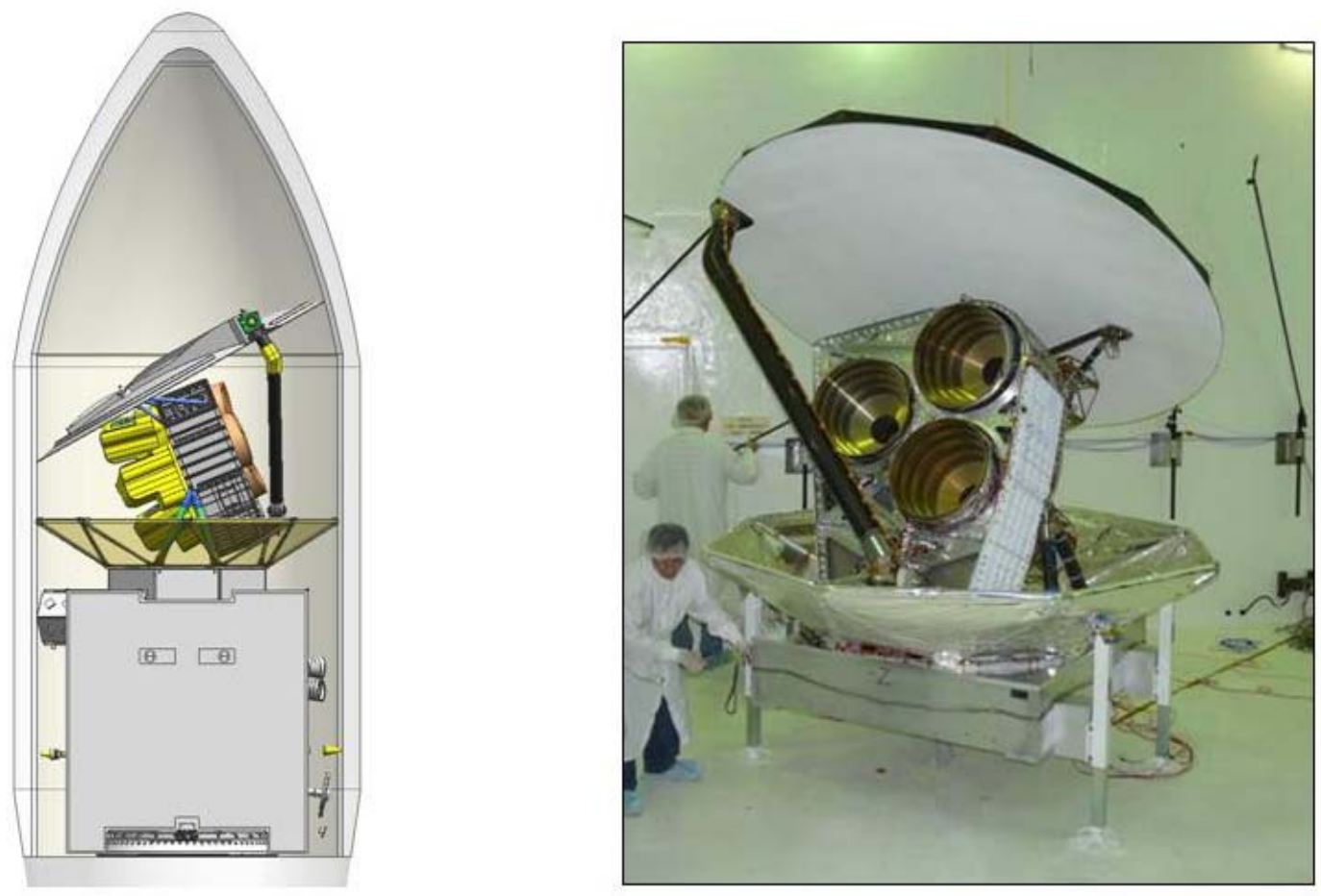

Figure 9. (Left) Drawing showing Aquarius in its stowed position inside the Delta-II launch shroud and (right) the actual flight hardware in its stowed configuration during acoustic testing at JPL. Aquarius mates to SAC -D along a ring just barely visible at the base of the sun shield. 


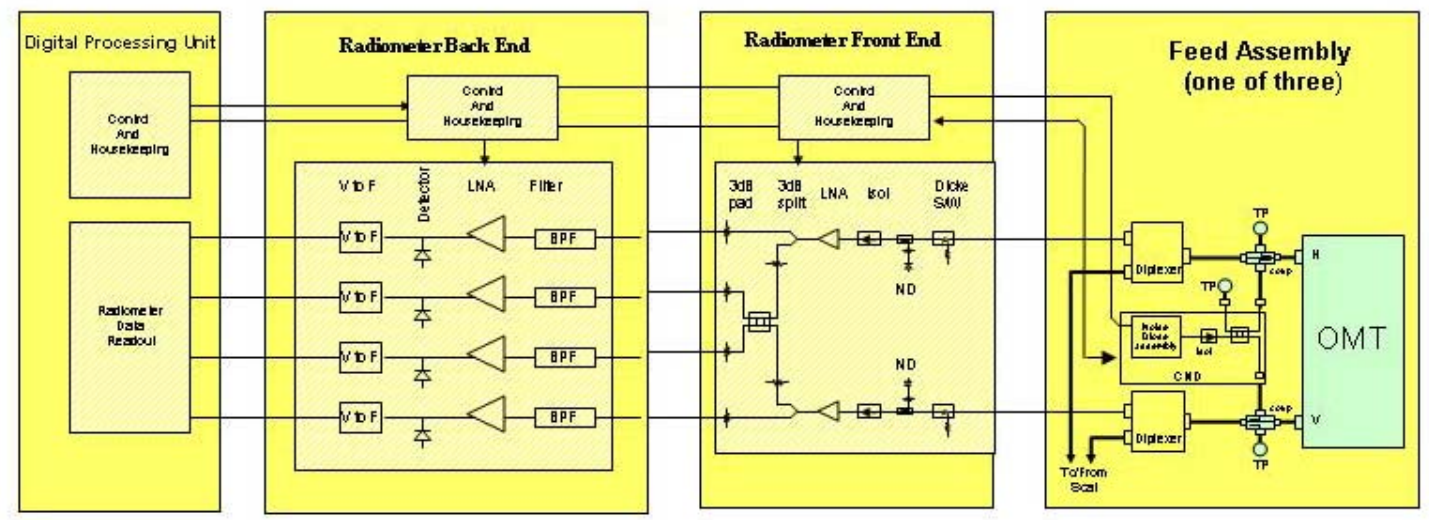

Figure 10: Radiometer schematic showing the major steps in processing. 